\title{
IL-4 and helminth infection downregulate MINCLE-dependent macrophage response to
}

3 Judith Schick ${ }^{*}$, Matthew Lacorcia ${ }^{\ddagger}$, Meltem Altunay*, Christoph Schubart ${ }^{\llbracket}$, Barbara

4 Bodendorfer ${ }^{*}$, Dennis Christensen ${ }^{\S}$, Christian Alexander**, Stefan Wirtz ${ }^{\S}$, David Vöhringer ${ }^{\Uparrow}$,

$5 \quad$ Clarissa Prazeres da Costa ${ }^{\ddagger}$, Roland Lang*

7 *Institut für Klinische Mikrobiologie, Immunologie und Hygiene, Universitätsklinikum

8 Erlangen, Friedrich-Alexander Universität Erlangen-Nürnberg, Germany

9 'Institut für Medizinische Mikrobiologie, Immunologie und Hygiene, Center for Global Health,

Technische Universität München, Germany

IInfektionsbiologische Abteilung, Universitätsklinikum Erlangen, Friedrich-Alexander

Universität Erlangen-Nürnberg, Germany

${ }^{\S}$ Adjuvant Research, Dept. of Infectious Disease Immunology, Statens Serum Institut,

Copenhagen, Denmark

${ }^{* *}$ Cellular Microbiology, Forschungszentrum Borstel, Leibniz Lung Center Borstel, Germany

${ }^{\S}$ Medizinische Klinik 1, Universitätsklinikum Erlangen, Friedrich-Alexander Universität

Running title: IL-4 regulation of MINCLE

${ }^{1}$ Funding information: Supported by grants from the Deutsche Forschungsgemeinschaft (GRK

C.P.d.C.)

${ }^{2}$ Correspondence: Roland Lang 


\section{Abstract}

The myeloid C-type lectin receptor (CLR) MINCLE senses the mycobacterial cell wall component trehalose-6,6-dimycolate (TDM). Recently, we found that IL-4 down-regulates MINCLE expression in macrophages. IL-4 is a hallmark cytokine in helminth infections, which appear to increase the risk for mycobacterial infection and active tuberculosis. Here, we investigated functional consequences of IL-4 and helminth infection on MINCLE-driven macrophage activation and Th1/Th17 adjuvanticity. IL-4 inhibited MINCLE and cytokine induction after macrophage infection with Mycobacterium bovis Bacille Calmette-Guerin (BCG). Infection of mice with BCG upregulated MINCLE on myeloid cells, which was inhibited by IL-4 plasmid injection and by infection with the nematode Nippostrongylus brasiliensis in monocytes. To determine the impact of helminth infection on MINCLEdependent immune responses, we vaccinated mice with a recombinant protein together with the MINCLE ligand Trehalose-6,6-dibehenate (TDB) as adjuvant. Concurrent infection with $N$. brasiliensis or with Schistosoma mansoni promoted T cell-derived IL-4 production and suppressed Th1/Th17 differentiation in the spleen. In contrast, helminth infection did not reduce Th1/Th17 induction by TDB in draining peripheral lymph nodes, where IL-4 levels were unaltered. Upon use of the TLR4-dependent adjuvant G3D6A, N. brasiliensis infection impaired selectively the induction of splenic antigen-specific Th1 but not of Th17 cells. Thus, helminth infection attenuated the Th17 response to MINCLE-dependent immunization in an organ-specific manner. Taken together, our results demonstrate down-regulation of MINCLE expression on monocytes and macrophages by IL-4 as a possible mechanism of thwarted Th17 vaccination responses by underlying helminth infection. 


\section{Introduction}

Tuberculosis kills more than 1 million humans each year and is easily spread by aerosol infection. Importantly, after exposure to Mycobacterium tuberculosis (MTB) by inhalation, only a minority of contacts develops active pulmonary disease with mycobacterial replication and destruction of lung tissue. In the majority of exposed people, inhaled MTB is either killed by the innate immune system of the lung, or triggers the development of granuloma structures around infected cells [1]. The development of specific CD4+ $\mathrm{T}$ cell responses then induces control of mycobacterial growth without achieving eradication of MTB, a status referred to as latency [1]. It is estimated that more than a quarter of the world's population is latently infected with MTB. Their life-long risk to develop reactivation tuberculosis is around $5 \%$ and is influenced by a variety of genetic and environmental factors.

Parasitic helminth infections with intestinal nematodes, filaria or trematodes affect an estimated number of $>2$ billion humans [2]. Similar to tuberculosis, helminth infections are often chronic and not acutely life-threatening. Epidemiologically, tuberculosis and helminth infections cooccur in many tropical and subtropical countries [3]. Immune responses to helminths in general are characterized by a strong Th2 component with production of IL-4, IL-5, IL-13, IL-10 and $\operatorname{IgE}[2]$, whereas protective immunity to MTB requires robust Th1 immunity and is possibly enhanced by Th17 cells $[4,5]$. These diametrically opposed immunological biases and effector mechanisms raise the question how MTB and parasitic helminths mutually influence each other in co-infected individuals [2]. Interestingly, helminth infection of household contacts of patients with active, smear-positive tuberculosis increased the rate of tuberculin skin test conversion indicating a higher risk to become infected [6]. Furthermore, active tuberculosis patients are more often co-infected with helminths than healthy counterparts [7, 8]. Furthermore, helminth co-infection is associated with more advanced disease in tuberculosis patients and with reduced 
production of IFN $\gamma$ but increased IL-10 [9]. These findings indicate that the type 2 immune bias in helminth-infected individuals can impair the development of protective adaptive immunity to MTB. In contrast, other studies showed that underlying helminth infection can promote a Th2 and regulatory T cell response to MTB with a reduced risk to develop open, smear-positive pulmonary tuberculosis [10]. In mice, infection with Nippostrongylus brasiliensis enhances bacterial load in the lung after MTB infection, an effect attributed to the action of alternatively activated macrophages [11].

Underlying helminth infection may also influence the response to vaccination with $M$. bovis Bacille Calmette-Guerin (BCG), which shows large geographic variation with reduced efficacy in countries with a high prevalence of worm infections $[12,13]$. Experimental infection of mice with Schistosoma (S.) mansoni or Heligmosomoides (H.) polygyrus impaired Th1 cell generation after vaccination with BCG $[14,15]$, although another study found that chronic enteric infection with $H$. polygyrus did not interfere with primary or memory $\mathrm{T}$ cell responses to BCG [16]. Thus, these results from experimental mouse models show that not all helminth infections have a similarly strong impact on protective immunity to MTB. Anthelminthic treatment prior to BCG administration led to increased IFN $\gamma$ and IL-12 production [17]. It is noteworthy that maternal helminth infection during pregnancy negatively affected the frequency of IFN $\gamma$-producing $\mathrm{T}$ cells in cord blood of neonates [18] and the development of Th1 immunity in BCG-vaccinated offspring [19]. However, attempts to enhance the immunogenicity of BCG vaccination by anthelminthic treatment of mothers during pregnancy were not successful [20].

Sensing of mycobacteria by the innate immune system is essential for a robust defense reaction, including the secretion of chemokines to attract leukocytes to the site of infection and the production of cytokines directing antigen-specific $\mathrm{T}$ cell responses towards Th1 and Th17 
differentiation. Mycobacteria contain a plethora of PAMPs, e.g. the TLR ligands $19 \mathrm{kDa}$ lipoprotein, lipoarabinomannan (LAM) and mycobacterial DNA rich in CpG motifs [21]. The hydrophobic cell wall of mycobacteria is especially rich in the glycolipid trehalose-6,6'dimycolate (TDM, aka the cord factor), which is sufficient to trigger granulomatous reactions in vivo [22], induces inflammatory cytokine production by macrophages [23] and confers the Th1/Th17 adjuvant activity known from Freund's Complete Adjuvant (CFA) [24]. TDM binds to the C-type lectin receptor (CLR) MINCLE (encoded by the Clec4e gene) [22, 25], which is inducibly expressed in macrophages [26] and associates with the adapter protein Fc receptor gamma chain (FcR $\gamma$, encoded by Fcerg1) [27]. Signaling by MINCLE requires binding of the kinase SYK to the phosphorylated ITAM of the FcR $\gamma$, and proceeds via the CARD9-BCL10MALT1 complex to activation of NFאB and expression of inflammatory target genes $[28,29]$. In addition to TDM, several additional glycolipids from the mycobacterial cell wall were recently identified as ligands for CLR, most of them like MINCLE members of the FcR $\gamma$ coupled DECTIN-2 family [30]. MCL, closely related to MINCLE and able to heterodimerize with it, also can bind TDM and in addition glycero-monomycolate [31, 32]; DECTIN-2 binds mannose-capped LAM [33]; and DCAR is a receptor for mycobacterial phosphatidyl-inositol mannosides [34]. The prototypic myeloid signaling CLR, DECTIN-1 directly recruits SYK through its non-classical ITAM [35]; it, too, binds and is activated by an yet unidentified mycobacterial ligand [36]. Since the signals emanating from the interaction of multiple CLR with MTB are transmitted through SYK-CARD9, it is not surprising that CARD9-deficient mice are highly susceptible to infection with MTB and succumb with high bacterial burden in the organs [37]. Knockout mice for individual CLR showed less severe phenotypes but were, dependent on the infection model employed, moderately more susceptible to infection [38-41].

Already in the first report on MINCLE, the inducible expression in response to TLR stimulation with LPS and by the cytokine TNF was reported [26]. Indeed, TNF is essential for the 
upregulation of MINCLE in macrophages stimulated with the cord factor and for the Th17 promoting effect of the adjuvant CAF01 that contains the MINCLE ligand TDB [42]. In contrast, the Th2 cytokines IL-4 and IL-13 downregulate expression of MINCLE, MCL and DECTIN-2, in human monocytes/macrophages and DC, as well as in mouse bone marrowderived macrophages $[43,44]$. This inhibitory effect of the Th2 cytokines IL-4 and IL-13 depends on the transcription factor STAT6 and is associated with a reduced production of GCSF and TNF by macrophages stimulated with the MINCLE ligand TDB, but not after stimulation with LPS [43]. Thus, expression of the DECTIN-2 family CLR MINCLE, MCL and DECTIN-2 is subject to a substantial regulation by the cytokines TNF and IL-4, which are key factors in type 1 and type 2 immune responses, respectively. Since type 2 immunity is a hallmark of many helminth infections, the question arises whether the expression and function of DECTIN-2 family CLR may be compromised during helminth infection in vivo [45].

Here, we have investigated the functional impact of IL-4 and helminth infection on myeloid responses to mycobacteria or the cord factor-based adjuvant TDB in vitro and in vivo. Our data show that IL-4 impairs MINCLE expression on monocytes in vivo, but does not interfere with phagocytosis of BCG. Underlying helminth infection attenuated immune responses to recombinant protein together with different adjuvants in the spleen but not in draining lymph nodes. The specific impairment of Th17 responses to MINCLE-dependent adjuvant indicates the contribution of downregulation of DECTIN-2 family CLR to vaccine antagonism induced by helminth infection. 


\section{Results}

IL-4 impairs upregulation of MINCLE and other DECTIN-2 family CLR in macrophages

154

stimulated with $B C G$

In previous work, we observed that IL-4 downregulates expression of MINCLE, MCL and DECTIN-2 when macrophages were stimulated with the MINCLE-ligand TDB, but not after triggering TLR4 with LPS [43]. Since mycobacteria contain multiple ligands for CLR and TLR, we were interested whether IL-4 has any impact on changes in DECTIN-2 family CLR expression in macrophages stimulated with M. bovis BCG (Fig. 1). Stimulation of BMM with BCG caused the strongest induction of MINCLE (up to 400-fold after 48 hours) and was reduced significantly by IL-4 (Fig. 1A). A similar pattern of inducibility and regulation by IL4 was observed for DECTIN-2 and MCL, albeit the increases at the mRNA level were more moderate (e.g. 50-fold for DECTIN-2 and 8-fold for MCL after stimulation with BCG) (Fig. 1B, C). IL-4 did not inhibit, but actually increased expression of DECTIN-1 (Fig. 1D), confirming a selective impact on DECTIN-2 family CLR. The inhibitory effect of IL-4 on BCGinduced expression of MINCLE was also evident at the protein level, when analysed by flow cytometry (Fig. 1E).

\section{IL-4 does not affect phagocytosis of BCG, but inhibits cytokine production}

Several CLR, including DECTIN-2 and MCL, are phagocytic receptors [46, 47]. Therefore, we next measured phagocytosis of fluorescent BCG (expressing DsRed) by flow cytometry in the presence or absence of IL-4 (Fig. 2A). BMM infected with BCG-DsRed in different MOI dosedependently ingested the mycobacteria, IL-4 had no impact on phagocytosis after 6 hours (not shown) and 24 hours (Fig. 2A). In contrast, the high levels of the cytokines G-CSF and TNF in supernatants of BMM infected with BCG were significantly reduced by co-treatment with IL4 (Fig. 2B), extending our previous results for TDB [43] to the response induced by whole 
mycobacteria. Stimulation of BMM deficient in MINCLE or in FcR $\gamma$ chain, the adapter protein used by MINCLE, MCL and DECTIN-2, with BCG led to a reduced production of TNF and GCSF, confirming the contribution of this receptor to macrophage activation by mycobacteria [22, 25] (Fig. 2B). Of interest, the inhibitory effect of IL-4 was still visible in MINCLEdeficient BMM for G-CSF but not for TNF; in addition, it was much less pronounced than in WT BMM (Fig. 2B), indicating that downregulation of MINCLE is a prominent mechanism of IL-4-induced impairment of macrophage cytokine production to mycobacteria.

\section{Overexpression of IL-4 inhibits MINCLE expression after intraperitoneal infection with BCG}

Given the impact of IL-4 on BCG-induced MINCLE expression in vitro, we next used intraperitoneal infection of mice with BCG for analysis of MINCLE regulation by IL-4 in vivo. Hydrodynamic injection of mini-circle DNA encoding IL-4 was used to overexpress IL-4 from hepatocytes in vivo [48]. Serum levels of IL-4 after injection of 0.25 and $0.5 \mu \mathrm{g}$ IL-4-encoding mini-circle DNA ranged between 1 and $2 \mathrm{ng} / \mathrm{ml}$, whereas IL-4 was not detectable in control mice (Fig. 3A). Peritoneal lavage cells were obtained 24 hours after i.p. infection with $4 \times 10^{7}$ CFU BCG and MINCLE expression on Ly6 $\mathrm{C}^{\text {hi }}$ monocytes and $\mathrm{Ly} 6 \mathrm{G}^{+}$neutrophils was analysed by flow cytometry (Fig. 3B, gating strategy). Compared to the PBS control mice, MINCLE cell surface expression increased after BCG-infection in monocytes and in neutrophils, which was abrogated by IL-4 overexpression specifically in monocytes but not neutrophils (Fig. 3C).

Co-infection with Nippostrongylus brasiliensis impairs MINCLE upregulation on peritoneal monocytes, but does not reduce phagocytosis, upon BCG infection

Infection with the hookworm $N$. brasiliensis induces a strong Th2 response characterized by high levels of IL-4. We therefore asked whether pre-existing infection with $N$. brasiliensis interferes with MINCLE expression on myeloid cells during mycobacterial infection. The peritoneal cavity of $N$. brasiliensis-infected mice contained a much higher proportion of 
SiglecF $^{+}$eosinophils (nearly $40 \%$ compared to $10 \%$ in controls), whereas the fraction of Ly $6 \mathrm{C}^{\text {hi }}$ monocytes was reduced (from $30 \%$ to $20 \%$ ), and the low percentage of resident monocytes/macrophages was not altered by helminth infection (Fig. 3D). Eosinophils were negative for MINCLE surface staining. MINCLE staining on inflammatory monocytes from BCG-infected mice was significantly reduced when co-infected with $N$. brasiliensis compared to control mice infected only with BCG (Fig. 3E). In contrast, the cell surface expression of MINCLE on neutrophils was not altered by underlying N. brasiliensis infection (Fig. 3E). The use of fluorescent BCG-DsRed enabled us to determine the cell types and percentages of peritoneal cells that had ingested mycobacteria 24 hours after injection (Fig. 3F). While on average $12 \%$ of Ly $6 \mathrm{C}^{\text {hi }}$ monocytes contained BCG-DsRed, no specific signal was measurable for the peritoneal neutrophils. Co-infection with $N$. brasiliensis did not change the phagocytosis of BCG by inflammatory monocytes in the peritoneal cavity (Fig. 3F).

Co-infection with N. brasiliensis or with Schistosoma mansoni suppresses Th1/Th17 induction

Downregulation of MINCLE expression on monocytes of mice with $N$. brasiliensis infection led us to ask whether vaccination responses to protein antigen induced by a MINCLE-dependent adjuvant would be inhibited by helminth infections. We investigated this question in chronic (non-transient) S. mansoni and acute (transient) N. brasiliensis infection models. Infected and control mice were immunized with the recombinant fusion protein $\mathrm{H} 1$, comprising the MTB antigens Ag85B and ESAT-6, adsorbed to the adjuvant CAF01 (a combination of the MINCLE ligand TDB incorporated into cationic liposomes) [49]. Subcutaneous injection of H1/CAF01 is known to induce robust IFN $\gamma$ and IL-17 production by $\mathrm{T}$ cells within seven days that is dependent on MINCLE-FcR $\gamma$ as well as on MyD88 signalling [50]. 
immunity, which dominates in the later phase of infection after 8-9 weeks. We therefore immunized mice infected with $S$. mansoni in this chronic phase subcutaneously with H1/CAF01 in the flank of the mice (Fig. 4A). We first analysed whether schistosomal infection indeed enhanced IL-4 production by T cells (Fig. 4B). While only very low levels of IL-4 were detectable in the supernatants of draining lymph node cells, splenocytes of $S$. mansoni-infected mice produced significant amounts of IL-4 when stimulated with anti-CD3 in vitro. Thus, $S$. mansoni-infection generated a Th2 milieu in the spleen, but not in the inguinal lymph node. Induction of antigen-specific Th1 and Th17 cells, detected by robust secretion of IFN $\gamma$ and IL17, respectively, was observed after immunization in both lymph nodes and spleen (Fig. 4C and D). Infection with $S$. mansoni had not impact on H1-specific or anti-CD3-induced production of IFN $\gamma$, IL-17 and of IL-10 from draining inguinal lymph nodes (Fig. 4C). In contrast, the antigen-specific splenocyte responses to $\mathrm{H} 1$ were strongly reduced in the case of IFN $\gamma$, IL-17 and also for IL-10 (Fig. 4D). S. mansoni infection also suppressed IFN $\gamma$, but not IL-17 production triggered by polyclonal anti-CD3 stimulation, whereas secretion of IL-10 was much higher from splenocytes of $S$. mansoni-infected mice (Fig. 4D). Together, these data show that S. mansoni-infection establishes a Th2 environment in the spleen but not in the inguinal lymph nodes, which corresponds to suppression of Th1 and Th17 responses after CAF01-adjuvanted immunization in splenocytes but has no impact on draining lymph node cells.

To determine whether $S$. mansoni-induced inhibition of antigen-specific immune responses by splenocytes, but not draining lymph node cells, was specific for the MINCLE-dependent adjuvant CAF01, we immunized mice with H1 together with the TLR9 ligand CpG ODN 1826 as adjuvant. Using the same protocol as before for H1/CAF01, we observed, as demonstrated previously [28], strong induction of IFN $\gamma$-producing T cells but a lack of IL-17 production upon

252 restimulation of draining lymph node cells or splenocytes (Fig. 4E, F). Thus, it was not possible 253 to compare inhibition of Th17 responses by helminth infection between adjuvants. However, $S$. 
CD3-stimulation were unaffected (Fig. 4E, F). Similar to the impact on immunization with

CAF01, S. mansoni infection strongly reduced antigen-specific and non-specific IFN $\gamma$ secretion

caused a general suppression of the splenic Th1 response to immunization, regardless whether the MINCLE-dependent adjuvant CAF01 was used or the TLR9-dependent CpG ODN 1826.

To address the effect of transient helminth infection, mice were injected subcutaneously with of cells in the draining inguinal lymph nodes 7 days after immunization was strongly increased compared to non-vaccinated mice, but significantly reduced in mice infected with $N$. brasiliensis; in contrast, the number of splenocytes was unaltered by helminth infection (Fig.

Th2 T cells was only detected in spleens of $N$. brasiliensis-infected mice but not in their popliteal and inguinal lymph nodes (Fig. 5D). Upon restimulation of lymph node cells with H1 in vitro, the antigen-specific production of IFN $\gamma$, IL-17 or IL-10 was not affected by $N$. generated significantly less IFN $\gamma$ and IL-17, but not IL-10, when restimulated with H1 antigen, whereas for polyclonal stimulation with anti-CD3 antibody only a reduction for IFN $\gamma$ was observed (Fig. 5F). When mice were immunized with H1 together with the TLR4-dependent adjuvant G3D6A, IFN $\gamma$ production by splenocytes was diminished in mice infected with $N$. brasiliensis, whereas antigen-specific secretion of IL-17, IL-10 and IL-4 were not changed (Fig. 
281 Together, these results indicate that underlying $N$. brasiliensis infection attenuated cell expansion in the draining lymph node, yet the differentiation toward Th1/Th17 at this site was

283 not affected. In contrast, hookworm infection did interfere with antigen-specific IFN $\gamma$ and IL-

28417 production by splenic T cells, correlating with strongly enhanced production of IL-4 by splenocytes (but not draining lymph node cells). The inhibitory effect of infection on IFN $\gamma$

286 appears to be general, antigen- and adjuvant-non-specific, because it was also observed after 287 polyclonal $\mathrm{T}$ cell stimulation and independent of the pattern recognition receptor pathway 288 triggered by the adjuvant used. In contrast, the impairment of Th17 induction in the spleen by N. brasiliensis was specific for the MINCLE-dependent CAF01. Taken together, immunization experiments in two helminth infection models demonstrated organ-specific inhibition of Th dependent IL-17 production. 


\section{Discussion}

In this study, we show for the first time that IL-4 impairs MINCLE expression and function in vivo. Two different models of helminth infection revealed an organ-specific impairment of Th17 induction by the MINCLE-dependent adjuvant CAF01 in the spleen. These findings establish an in vivo impact of IL-4 on the expression and function of MINCLE that may have important consequences for the detection of and the response to mycobacteria and their cell wall glycolipids in infection or vaccination.

In previous work, we have found that IL-4 downregulates expression of DECTIN-2 family CLRs in murine and human macrophages and DC [43]. Here, we first extended these findings by showing that upregulation of these CLR by BCG was also impaired by IL-4 in BMM. Importantly, using overexpression of IL-4 in vivo by hydrodynamic injection of minicircle DNA, the upregulation of MINCLE on monocytes recruited after BCG infection to the peritoneum was strongly inhibited. This effect was cell type-specific, as it was not observed on recruited neutrophils, and it was also caused by infection with $N$. brasiliensis.

IL-4 and N. brasiliensis infection did not interfere with phagocytosis of BCG in vitro or in vivo, showing that high level expression of DECTIN-2 family CLR is not required for phagocytosis of mycobacteria. This may seem surprising, as DECTIN-2 and MCL are phagocytic receptors $[51,52]$, and mycobacteria strongly express ligands for both receptors (mannans and TDM). A lack of DECTIN-2 family CLR appears to be compensated by the large number of other receptors contributing to phagocytosis of mycobacteria, including the mannose receptor CD206, integrins like CD11b, or the inhibitory CLR DC-SIGN [53-55].

Importantly, IL-4-treated macrophages not only down-regulated DECTIN-2 family CLR, but in addition produced significantly less cytokines after stimulation with BCG. A similar reduction in G-CSF and TNF production was observed here in MINCLE- and FcR $\gamma$-deficient 
BMM. These observations suggests that IL-4 produced during helminth infection could interfere with the initial sensing of invading mycobacteria by pulmonary macrophages and thereby mute the generation of an inflammatory chemokine/cytokine as well as an antimicrobial response. If so, impaired detection of inhaled MTB by alveolar and lung macrophages may favour intracellular mycobacterial survival and replication, providing a mechanism underlying the reported increase in tuberculin skin test conversion reported for helminthinfected household contacts of patients with smear-positive tuberculosis [6]. Whether IL-4 impairs functional macrophage responses to mycobacteria primarily through downregulation of MINCLE and DECTIN-2 family CLRs or by inhibiting other cytokine-inducing pathways is an open question that needs to be investigated in future work.

In addition to the response of macrophages to BCG, we investigated how type 2 immune bias during helminth infections impacts on the Th cell differentiation after recombinant subunit vaccination with MINCLE-dependent and -independent adjuvants. Induction of Th17 immunity triggered by the MINCLE-dependent adjuvant CAF01 was suppressed in two models of helminth infection in the spleen, but not in the draining popliteal and inguinal lymph nodes. This organ-specific impact of infection with $N$. brasiliensis and S. mansoni on splenic Th cell differentiation was associated with a stronger Th2 bias in the spleen, as demonstrated by the robustly increased levels of IL-4 and IL-10 released by splenocytes, but not draining lymph node cells, from worm-infected mice after polyclonal stimulation with anti-CD3 (Figs. 4 and 5). Compartmentalized overexpression of IL-10 in the spleens but not lymph nodes has been described before in mice with chronic schistosomiasis [56]. Our data suggest that such a 338 restriction of Th2 bias to the spleen also applies to IL-4 producing $\mathrm{T}$ cells in both helminth 339 infections. 
of cells with recombinant H1. However, the cellularity of the lymph nodes was significantly diminished by $N$. brasiliensis, suggesting that the total number of antigen-specific Th1 / Th17 cells in the draining lymph nodes is reduced by co-existent worm infection. Decreased peripheral lymph node size and cellularity has been reported in mice infected with the enteric helminth $H$. polygyrus and was associated with a dampened immune response to infection with BCG, affecting primarily B and T lymphocytes [57]. In the H. polygyrus model, the gut-draining mesenteric lymph nodes were increased in size, suggesting that atrophy of peripheral lymph nodes was due to a redistribution of lymphocytes [57]. Furthermore, in mice infected with Helicobacter pylori, we have recently shown that concomitant schistosome infection lead to a redistribution of bacterial-specific $\mathrm{CXCR} 3+\mathrm{T}$ cells resulting in reduced bacterial growth control [58]. Cell numbers and size of lymph nodes are controlled by entry of lymphocytes via the high endothelial venules and exit through the efferent lymphatics.

While the inhibition of IFN $\gamma$ production by splenocytes from helminth-infected mice was impaired also after immunization with the TLR4 ligand G3D6A and the TLR9 ligand CpG ODN as adjuvants, IL-17 production was specifically impaired when the MINCLE-dependent

357 CAF01 was the adjuvant. In addition, antigen-non-specific production of IFN $\gamma$ by polyclonal anti-CD3 stimulation was also inhibited in splenocytes from helminth-infected mice, suggesting a general inhibitory effect of $N$. brasiliensis and $S$. mansoni infection that was not observed for production of IL-17. Thus, underlying helminth infection affects the CAF01-induced antigenspecific Th cell response in the spleen in a manner that could be explained by down-regulation of MINCLE expression. Whether this is indeed the case needs to be further investigated in future studies comparing myeloid cells in spleen, peripheral lymph node and subcutaneous injection site tissue. Detection and quantification of MINCLE surface protein on myeloid cells from tissues by flow cytometry is unfortunately complicated by the fact that proteolytic agents commonly used for enzymatic tissue-dissociation cause a near complete loss of specific staining 
[59]. For this reason, we employed here the intraperitoneal BCG-infection model for assessment of IL-4/helminth effects on myeloid cells in vivo, because it allowed the direct flow cytometric staining of peritoneal exudate cells without the need for enzymatic tissue digestion.

Interestingly, application of schistosome eggs, a strong inducer of IL-4 and IL-13 production in vivo, prior to infection of mice with Salmonella typhimurium downregulated the Th17 response in the gut mucosa and impaired the clearance of the bacteria from the gut [60]. As the Salmonella cell wall contains trehalose phospholipids that bind to and activate MINCLE [61], it is possible that induction of IL-17-producing cells during infection requires MINCLE and may be inhibited by schistosome eggs through IL-4/IL-13-induced downregulation of the receptor. Alternatively, IL-4 and IL-10 present in the spleen during helminth infection may act directly on antigen-specific Th cell differentiation after immunization and block Th17 [62, 63] and Th1 bias [64].

More generally, down-regulation of other PRR in addition to DECTIN-2 family CLR during acute or chronic helminth infection may also have a negative impact on vaccines comprising specific PAMPs as adjuvants. Indeed, several papers have demonstrated a diminished baseline expression of TLR2 and TLR9 patients with filarial infection $[65,66]$. Underlying infection with hookworm or filaria were found to down-regulate Th1 and Th17 responses in individuals with latent tuberculosis $[67,68]$. Certainly, helminth-induced immune regulation can interfere by diverse and manifold mechanisms with Th1/Th17 adaptive immunity. It will be worthwhile to investigate further, in animal models and in human patients with helminth infection, whether impaired DECTIN-2 family CLR expression is a significant contributor to thwarting of these protective anti-mycobacterial $\mathrm{T}$ cell responses. 


\section{Methods}

Mice

392

C57BL/6 wildtype, MINCLE knockout $\left(C l e c 4 e^{-/-}\right)$and FcR $\gamma$ knockout $\left(F c e r g 1^{-/-}\right)$mice were bred under specific pathogen-free (SPF) conditions at the "Präklinische Experimentelle Tierzentrum" (PETZ) of the Medical Faculty in Erlangen. Clec $4 e^{-/-}$mice were generated by the Consortium for Functional Glycomics [69] and used with permission. Fcerg $1^{-/-}$mice [70] were kindly provided by Dr. Falk Nimmerjahn. C57BL/6N mice were purchased from Charles River Laboratories. All mouse experiments were approved by the "Regierung von Unterfranken" (protocol number 55.2.2-2532-543) and the "Regierung of Oberbayern" (protocol number ROB-55.2 Vet_02-17-145). Male mice between 8 and 12 weeks of age were used for in vivo experiments.

\section{Bacteria}

Mycobacterium bovis (BCG) was grown in Middlebrook 7H9 broth supplemented with $10 \%$ OADC-enrichment medium and $0.05 \%$ Tween 80 in small cell culture flasks constantly shaking at $125 \mathrm{rpm}$ at $37^{\circ} \mathrm{C}$ to an $\mathrm{OD}_{600} \sim 1-2$. Prior to in vitro stimulation, $\mathrm{BCG}$ were washed with PBS and diluted in cDMEM.

\section{Hydrodynamic injection of IL-4 minicircle DNA}

To investigate IL-4 derived effects on immunization responses or BCG-infections in mice, we utilized a technique that leads to a systemic overexpression of IL-4. A minicircle DNA vector that encodes the gene for IL-4, but lacks further bacterial elements in comparison to conventional plasmids, was hydrodynamically injected intravenously in the tail vein of fiveweek old male mice [71]. $0.5 \mu \mathrm{g}$ of IL-4 was injected in $2 \mathrm{ml}$ Ringer solution in under 10 seconds per mouse. 


\section{Helminth infections}

All Schistosoma mansoni infection experiments were performed at TU Munich. C57BL/6 mice were infected subcutaneously as described previously [58] with 100 cercariae from the NMRI strain (originally from Puerto Rico) of S. mansoni in $100 \mu 1$ PBS shed by infected Biomphalaria glabrata snails, provided by the NIAID Schistosomiasis Resource Center of Biomedical Research Institute (Rockville, MD) through NIH-NIAID Contract HHSN272201700014I for distribution through BEI Resources. Mice were vaccinated after 8 weeks of infection, when parasite egg-induced Th2 immune responses begin to peak.

The Nippostrongylus brasiliensis life cycle was maintained in rats. N. brasiliensis larvae were cultured in a mixture of charcoal and feces of infected rats in petri dishes for 15-40 days at $37^{\circ} \mathrm{C}$. Subsequently, third-stage (L3) larvae were harvested with $10 \mathrm{ml}$ of $0.9 \%$ saline and transferred to a Baermann apparatus. Within 1h larvae descended to the bottom of the funnel. Larvae were then transferred to a fresh $50 \mathrm{ml}$ tube and extensively washed by repeating steps of sedimentation and exchange of saline. C57BL/6 mice were infected subcutaneously with 500 L3 larvae in $200 \mu \mathrm{l}$ PBS in the flank of each mouse using a $25 \mathrm{G}$ needle. All worms were expelled completely within 10 days.

\section{$B C G$ infection of mice}

10 days after $N$. brasiliensis infection, or 2 days after hydrodynamic injection of IL-4 minicircle DNA, mice were infected intraperitoneally with $40 \times 10^{6} \mathrm{CFU}$ of $M$. bovis $\mathrm{BCG}$ in a volume of $200 \mu 1$ PBS using a 27-G needle. PBS-injected mice as well as completely naïve mice were used as controls. Mice were sacrificed $24 \mathrm{~h}$ post infection.

\section{Immunizations}

Mice were immunized subcutaneously with $50 \mu \mathrm{l}$ of a mixture of $1 \mu \mathrm{g} \mathrm{H}$, a fusion protein of the MTB antigens Ag85B and ESAT-6, and the respective adjuvants (CAF01, CpG ODN 1826, 
or G3D6A) in the footpads of the hind legs or in the flank as indicated in the Figure legends.

443 CAF01 is composed of TDB and cationic dimethyldioctadecylammonium (DDA) liposomes 444 and has been described in detail before [49]. CpG ODN 1826 is a phosphorothioate-protected 445 oligonucleotide and was synthetized by TIB MOLBIOL (Berlin, Germany). G3D6A is a 446 liposomal adjuvant formulation. It is comprised of the synthetic TLR4 ligand 3-O-de-acyl447 hexaacyl-monophoshoryl lipid A (3D-6A-SMPLA, 3D(6-acyl)-PHAD®) manufactured as 448 cGMP product by Avanti Polar Lipids Inc. (Alabaster, Alabama,U.S.A) and embedded in a 449 matrix of 1,2-dimyristoyl-sn-glycero-3-phosphocholine (DMPC), 1,2-Dimyristoyl-sn-glycero3-phosphoglycerol (DMPG) and Cholesterol (Molar ration: 9:1:7.5) in an aqueous suspension buffered with PBS. Footpad swelling was monitored regularly and measured prior to 452 immunization as well as every second day post immunization. On day 7 post immunization, inguinal and popliteal lymph nodes were analysed.

Isolation and culture of bone marrow-derived macrophages (BMM)

Bone marrow cells were differentiated to BMM for 6-7 days in complete Dulbecco's Modified Eagle Medium containing $10 \%$ FCS, $50 \mu \mathrm{M} \beta$-mercaptoethanol and Penicillin/Streptomycin (cDMEM) supplemented with $10 \%$ L929-cell conditioned medium (LCCM) as a source of MCSF.

\section{Stimulation of BMM}

462 BMM were stimulated with plate-coated TDB (Polar Avanti, $5 \mu \mathrm{g} / \mathrm{ml}$ ), using isopropanol as a mock control, as described [28], LPS (E. coli serotype O55:B5, Sigma, 10ng/ml), CpG ODN 1826 (TIB MOLBIOL, $0.5 \mu \mathrm{M}$ ), or with BCG at the indicated MOI. 
Inguinal and popliteal lymph nodes were collected and meshed through a $70 \mu \mathrm{m}$ nylon filter to get a single cell suspension. $5 \times 10^{5}$ cells were stimulated in 96-well U-bottom plates with H1 (1 $\mu \mathrm{g} / \mathrm{ml})$, soluble anti-CD3 $(0.5 \mu \mathrm{g} / \mathrm{ml})$ or left untreated (mock) for $96 \mathrm{~h}$.

RNA was isolated using Trifast (Peqlab) and transcribed to cDNA (High capacity cDNA and of the genes of interest was analyzed by quantitative real time PCR (qRT-PCR). All primers and probes were selected from the Roche Universal Probe Library (UPL). Ct values of the target genes were normalized to Hprt, calibrated to unstimulated cells, and depicted as fold change.

Secreted cytokines were analyzed by ELISA (R\&D Systems) from cell culture supernatants of stimulated BMM or lymph node cells.

\section{Flow cytometry}

483 Cell surface expression of MINCLE was analyzed by flow cytometry. Cells were blocked with anti-mouse CD16/32, stained with the primary antibody anti-MINCLE (clone 4A9, MBL, $1 \mu \mathrm{g} / \mathrm{ml}$ ), followed by anti-rat IgG1-APC (eBioscience). FACS data were acquired on a LSRFortessa $^{\mathrm{TM}}(\mathrm{BD})$ and analyzed using the software FlowJo (v10).

\section{Statistics}

489 GraphPad Prism software (version 8) was used for statistical analysis. Statistical significance was calculated using Mann Whitney U-test to compare two non-paired groups. $* \mathrm{p}<0.05, * * \mathrm{p}$ $<0.01, * * * \mathrm{p}<0.001$, ns $\mathrm{p}>0.05$ 


\section{Acknowledgements}

494

495 Animal husbandry by Manfred Kirsch, technical assistance by Nina Grohmann, and support by

496 Christian Bogdan is gratefully acknowledged. We thank Nathalie Thuma and Paul Haase for

497 help with N. brasiliensis infections.

498 This work was funded by Deutsche Forschungsgemeinschaft (GRK 1660-TP-A02 and LA

499 1262/8-1 to R.L., and CRC1181_A02 to D.V., and CO 1469/16-1 to C.P.d.C.). 


\section{References}

1. Pai M, Behr MA, Dowdy D, Dheda K, Divangahi M, Boehme CC, et al. Tuberculosis. Nat Rev Dis Primers. 2016;2:16076. Epub 2016/10/28. doi: 10.1038/nrdp.2016.76. PubMed PMID: 27784885.

2. Babu S, Nutman TB. Helminth-Tuberculosis Co-infection: An Immunologic Perspective. Trends Immunol. 2016;37(9):597-607. doi: 10.1016/j.it.2016.07.005. PubMed PMID: 27501916; PubMed Central PMCID: PMC5003706.

3. Salgame P, Yap GS, Gause WC. Effect of helminth-induced immunity on infections with microbial pathogens. Nat Immunol. 2013;14(11):1118-26. doi: 10.1038/ni.2736. PubMed PMID: 24145791.

4. Gopal R, Lin Y, Obermajer N, Slight S, Nuthalapati N, Ahmed M, et al. IL-23dependent IL-17 drives Th1-cell responses following Mycobacterium bovis BCG vaccination. Eur J Immunol. 2012;42(2):364-73. Epub 2011/11/22. doi: 10.1002/eji.201141569. PubMed PMID: 22101830; PubMed Central PMCID: PMCPMC3490408.

5. Monin L, Griffiths KL, Slight S, Lin Y, Rangel-Moreno J, Khader SA. Immune requirements for protective Th17 recall responses to Mycobacterium tuberculosis challenge. Mucosal immunology. 2015;8(5):1099-109. Epub 2015/01/30. doi: 10.1038/mi.2014.136. PubMed PMID: 25627812; PubMed Central PMCID: PMCPMC4517980.

6. Verhagen LM, Hermans PW, Warris A, de Groot R, Maes M, Villalba JA, et al. Helminths and skewed cytokine profiles increase tuberculin skin test positivity in Warao Amerindians. Tuberculosis (Edinb). 2012;92(6):505-12. doi: 10.1016/j.tube.2012.07.004. PubMed PMID: 22877977.

7. Elias D, Mengistu G, Akuffo H, Britton S. Are intestinal helminths risk factors for developing active tuberculosis? Tropical medicine \& international health : TM \& IH. 2006;11(4):551-8. doi: 10.1111/j.1365-3156.2006.01578.x. PubMed PMID: 16553939.

8. Tristao-Sa R, Ribeiro-Rodrigues R, Johnson LT, Pereira FE, Dietze R. Intestinal nematodes and pulmonary tuberculosis. Revista da Sociedade Brasileira de Medicina Tropical. 2002;35(5):533-5. PubMed PMID: 12621678.

9. Resende Co T, Hirsch CS, Toossi Z, Dietze R, Ribeiro-Rodrigues R. Intestinal helminth co-infection has a negative impact on both anti-Mycobacterium tuberculosis immunity and clinical response to tuberculosis therapy. Clin Exp Immunol. 2007;147(1):4552. doi: 10.1111/j.1365-2249.2006.03247.x. PubMed PMID: 17177962; PubMed Central PMCID: PMC1810442.

10. Abate E, Belayneh M, Idh J, Diro E, Elias D, Britton S, et al. Asymptomatic Helminth Infection in Active Tuberculosis Is Associated with Increased Regulatory and Th-2 Responses and a Lower Sputum Smear Positivity. PLoS neglected tropical diseases. 2015;9(8):e0003994. doi: 10.1371/journal.pntd.0003994. PubMed PMID: 26248316; PubMed Central PMCID: PMC4527760.

11. Potian JA, Rafi W, Bhatt K, McBride A, Gause WC, Salgame P. Preexisting helminth infection induces inhibition of innate pulmonary anti-tuberculosis defense by engaging the IL4 receptor pathway. J Exp Med. 2011;208(9):1863-74. doi: 10.1084/jem.20091473. PubMed PMID: 21825018; PubMed Central PMCID: PMC3171086.

12. Roy A, Eisenhut M, Harris RJ, Rodrigues LC, Sridhar S, Habermann S, et al. Effect of $B C G$ vaccination against Mycobacterium tuberculosis infection in children: systematic review 
and meta-analysis. Bmj. 2014;349:g4643. doi: 10.1136/bmj.g4643. PubMed PMID: 25097193; PubMed Central PMCID: PMC4122754.

13. Colditz GA, Brewer TF, Berkey CS, Wilson ME, Burdick E, Fineberg HV, et al. Efficacy of BCG vaccine in the prevention of tuberculosis. Meta-analysis of the published literature. JAMA. 1994;271(9):698-702. PubMed PMID: 8309034.

14. Elias D, Akuffo H, Pawlowski A, Haile M, Schon T, Britton S. Schistosoma mansoni infection reduces the protective efficacy of $\mathrm{BCG}$ vaccination against virulent Mycobacterium tuberculosis. Vaccine. 2005;23(11):1326-34. doi: 10.1016/j.vaccine.2004.09.038. PubMed PMID: 15661380.

15. Obieglo K, Feng X, Bollampalli VP, Dellacasa-Lindberg I, Classon C, Osterblad M, et al. Chronic Gastrointestinal Nematode Infection Mutes Immune Responses to Mycobacterial Infection Distal to the Gut. J Immunol. 2016;196(5):2262-71. doi: 10.4049/jimmunol.1500970. PubMed PMID: 26819205; PubMed Central PMCID: PMC4760231.

16. Rafi W, Bhatt K, Gause WC, Salgame P. Neither primary nor memory immunity to Mycobacterium tuberculosis infection is compromised in mice with chronic enteric helminth infection. Infect Immun. 2015;83(3):1217-23. doi: 10.1128/IAI.03004-14. PubMed PMID: 25605766; PubMed Central PMCID: PMC4333454.

17. Elias D, Wolday D, Akuffo H, Petros B, Bronner U, Britton S. Effect of deworming on human $\mathrm{T}$ cell responses to mycobacterial antigens in helminth-exposed individuals before and after bacille Calmette-Guerin (BCG) vaccination. Clin Exp Immunol. 2001;123(2):219-25. PubMed PMID: 11207651; PubMed Central PMCID: PMC1905995.

18. Gebreegziabiher D, Desta K, Desalegn G, Howe R, Abebe M. The effect of maternal helminth infection on maternal and neonatal immune function and immunity to tuberculosis. PLoS One. 2014;9(4):e93429. doi: 10.1371/journal.pone.0093429. PubMed PMID: 24710174; PubMed Central PMCID: PMC3977838.

19. Malhotra I, Mungai P, Wamachi A, Kioko J, Ouma JH, Kazura JW, et al. Helminthand Bacillus Calmette-Guerin-induced immunity in children sensitized in utero to filariasis and schistosomiasis. J Immunol. 1999;162(11):6843-8. PubMed PMID: 10352306.

20. Webb EL, Mawa PA, Ndibazza J, Kizito D, Namatovu A, Kyosiimire-Lugemwa J, et al. Effect of single-dose anthelmintic treatment during pregnancy on an infant's response to immunisation and on susceptibility to infectious diseases in infancy: a randomised, doubleblind, placebo-controlled trial. Lancet. 2011;377(9759):52-62. doi: 10.1016/S01406736(10)61457-2. PubMed PMID: 21176950; PubMed Central PMCID: PMC3018567.

21. Mortaz E, Adcock IM, Tabarsi P, Masjedi MR, Mansouri D, Velayati AA, et al. Interaction of Pattern Recognition Receptors with Mycobacterium Tuberculosis. J Clin Immunol. 2015;35(1):1-10. Epub 2014/10/15. doi: 10.1007/s10875-014-0103-7. PubMed PMID: 25312698; PubMed Central PMCID: PMCPMC4306732.

22. Ishikawa E, Ishikawa T, Morita YS, Toyonaga K, Yamada H, Takeuchi O, et al. Direct recognition of the mycobacterial glycolipid, trehalose dimycolate, by C-type lectin Mincle. J Exp Med. 2009;206(13):2879-88. doi: 10.1084/jem.20091750. PubMed PMID: 20008526; PubMed Central PMCID: PMC2806462.

23. Geisel RE, Sakamoto K, Russell DG, Rhoades ER. In vivo activity of released cell wall lipids of Mycobacterium bovis bacillus Calmette-Guerin is due principally to trehalose mycolates. J Immunol. 2005;174(8):5007-15. PubMed PMID: 15814731. 
24. Shenderov K, Barber DL, Mayer-Barber KD, Gurcha SS, Jankovic D, Feng CG, et al. Cord factor and peptidoglycan recapitulate the Th17-promoting adjuvant activity of mycobacteria through mincle/CARD9 signaling and the inflammasome. J Immunol. 2013;190(11):5722-30. doi: 10.4049/jimmunol.1203343. PubMed PMID: 23630357; PubMed Central PMCID: PMC3719989.

25. Schoenen H, Bodendorfer B, Hitchens K, Manzanero S, Werninghaus K, Nimmerjahn $\mathrm{F}$, et al. Cutting edge: Mincle is essential for recognition and adjuvanticity of the mycobacterial cord factor and its synthetic analog trehalose-dibehenate. J Immunol. 2010;184(6):2756-60. Epub 2010/02/19. doi: jimmunol.0904013 [pii]

10.4049/jimmunol.0904013. PubMed PMID: 20164423.

26. Matsumoto M, Tanaka T, Kaisho T, Sanjo H, Copeland NG, Gilbert DJ, et al. A novel LPS-inducible C-type lectin is a transcriptional target of NF-IL6 in macrophages. J Immunol. 1999;163(9):5039-48. PubMed PMID: 10528209.

27. Yamasaki S, Ishikawa E, Sakuma M, Hara H, Ogata K, Saito T. Mincle is an ITAMcoupled activating receptor that senses damaged cells. Nat Immunol. 2008;9(10):1179-88. PubMed PMID: 18776906.

28. Werninghaus K, Babiak A, Gross O, Holscher C, Dietrich H, Agger EM, et al. Adjuvanticity of a synthetic cord factor analogue for subunit Mycobacterium tuberculosis vaccination requires FcRgamma-Syk-Card9-dependent innate immune activation. J Exp Med. 2009;206(1):89-97. PubMed PMID: 19139169.

29. Ostrop J, Lang R. Contact, Collaboration, and Conflict: Signal integration of Sykcoupled C-type lectin receptors. Journal of Immunology. 2017;198:1403-14.

30. Ishikawa E, Mori D, Yamasaki S. Recognition of Mycobacterial Lipids by Immune Receptors. Trends Immunol. 2017;38(1):66-76. doi: 10.1016/j.it.2016.10.009. PubMed PMID: 27889398.

31. Furukawa A, Kamishikiryo J, Mori D, Toyonaga K, Okabe Y, Toji A, et al. Structural analysis for glycolipid recognition by the C-type lectins Mincle and MCL. Proc Natl Acad Sci U S A. 2013;110(43):17438-43. doi: 10.1073/pnas.1312649110. PubMed PMID: 24101491; PubMed Central PMCID: PMC3808641.

32. Miyake Y, Toyonaga K, Mori D, Kakuta S, Hoshino Y, Oyamada A, et al. C-type lectin MCL is an FcRgamma-coupled receptor that mediates the adjuvanticity of mycobacterial cord factor. Immunity. 2013;38(5):1050-62. doi: 10.1016/j.immuni.2013.03.010. PubMed PMID: 23602766.

33. Yonekawa A, Saijo S, Hoshino Y, Miyake Y, Ishikawa E, Suzukawa M, et al. Dectin2 is a direct receptor for mannose-capped lipoarabinomannan of mycobacteria. Immunity. 2014;41(3):402-13. doi: 10.1016/j.immuni.2014.08.005. PubMed PMID: 25176311.

34. Toyonaga K, Torigoe S, Motomura Y, Kamichi T, Hayashi JM, Morita YS, et al. CType Lectin Receptor DCAR Recognizes Mycobacterial Phosphatidyl-Inositol Mannosides to Promote a Th1 Response during Infection. Immunity. 2016;45(6):1245-57. doi: 10.1016/j.immuni.2016.10.012. PubMed PMID: 27887882.

35. Rogers NC, Slack EC, Edwards AD, Nolte MA, Schulz O, Schweighoffer E, et al. Syk-dependent cytokine induction by Dectin-1 reveals a novel pattern recognition pathway for C type lectins. Immunity. 2005;22(4):507-17. PubMed PMID: 15845454.

36. Rothfuchs AG, Bafica A, Feng CG, Egen JG, Williams DL, Brown GD, et al. Dectin-1 Interaction with Mycobacterium tuberculosis Leads to Enhanced IL-12p40 Production by Splenic Dendritic Cells. J Immunol. 2007;179(6):3463-71. PubMed PMID: 17785780. 
37. Dorhoi A, Desel C, Yeremeev V, Pradl L, Brinkmann V, Mollenkopf HJ, et al. The adaptor molecule CARD9 is essential for tuberculosis control. J Exp Med. 2010;207(4):77792. doi: 10.1084/jem.20090067. PubMed PMID: 20351059; PubMed Central PMCID: PMC2856020.

38. Wilson GJ, Marakalala MJ, Hoving JC, van Laarhoven A, Drummond RA, Kerscher $\mathrm{B}$, et al. The C-type lectin receptor CLECSF8/CLEC4D is a key component of antimycobacterial immunity. Cell host \& microbe. 2015;17(2):252-9. doi:

10.1016/j.chom.2015.01.004. PubMed PMID: 25674984; PubMed Central PMCID: PMC4334100.

39. Behler F, Maus R, Bohling J, Knippenberg S, Kirchhof G, Nagata M, et al. Macrophage-inducible C-type lectin Mincle-expressing dendritic cells contribute to control of splenic Mycobacterium bovis BCG infection in mice. Infect Immun. 2015;83(1):184-96. doi: 10.1128/IAI.02500-14. PubMed PMID: 25332121; PubMed Central PMCID: PMC4288868.

40. Behler F, Steinwede K, Balboa L, Ueberberg B, Maus R, Kirchhof G, et al. Role of Mincle in alveolar macrophage-dependent innate immunity against mycobacterial infections in mice. J Immunol. 2012;189(6):3121-9. doi: 10.4049/jimmunol.1201399. PubMed PMID: 22869905.

41. Lee WB, Kang JS, Yan JJ, Lee MS, Jeon BY, Cho SN, et al. Neutrophils Promote Mycobacterial Trehalose Dimycolate-Induced Lung Inflammation via the Mincle Pathway. PLoS Pathog. 2012;8(4):e1002614. doi: 10.1371/journal.ppat.1002614. PubMed PMID: 22496642; PubMed Central PMCID: PMC3320589.

42. Schick J, Schafer J, Alexander C, Dichtl S, Murray PJ, Christensen D, et al. Cutting Edge: TNF Is Essential for Mycobacteria-Induced MINCLE Expression, Macrophage Activation, and Th17 Adjuvanticity. J Immunol. 2020;205(2):323-8. Epub 2020/06/17. doi: 10.4049/jimmunol.2000420. PubMed PMID: 32540999.

43. Hupfer T, Schick J, Jozefowski K, Voehringer D, Ostrop J, Lang R. Stat6-Dependent Inhibition of Mincle Expression in Mouse and Human Antigen-Presenting Cells by the Th2 Cytokine IL-4. Frontiers in immunology. 2016;7:423. doi: 10.3389/fimmu.2016.00423. PubMed PMID: 27790218; PubMed Central PMCID: PMC5063851.

44. Ostrop J, Jozefowski K, Zimmermann S, Hofmann K, Strasser E, Lepenies B, et al. Contribution of MINCLE-SYK Signaling to Activation of Primary Human APCs by Mycobacterial Cord Factor and the Novel Adjuvant TDB. J Immunol. 2015;195(5):2417-28. doi: 10.4049/jimmunol.1500102. PubMed PMID: 26202982.

45. Lang R, Schick J. Review: Impact of Helminth Infection on Antimycobacterial Immunity-A Focus on the Macrophage. Frontiers in immunology. 2017;8:1864. doi: 10.3389/fimmu.2017.01864. PubMed PMID: 29312343; PubMed Central PMCID: PMC5743664.

46. Ifrim DC, Bain JM, Reid DM, Oosting M, Verschueren I, Gow NA, et al. Role of Dectin-2 for host defense against systemic infection with Candida glabrata. Infect Immun. 2014;82(3):1064-73. Epub 2013/12/18. doi: 10.1128/IAI.01189-13. PubMed PMID: 24343653; PubMed Central PMCID: PMCPMC3957982.

47. Graham LM, Gupta V, Schafer G, Reid DM, Kimberg M, Dennehy KM, et al. The Ctype lectin receptor CLECSF8 (CLEC4D) is expressed by myeloid cells and triggers cellular activation through Syk kinase. J Biol Chem. 2012;287(31):25964-74. doi: 10.1074/jbc.M112.384164. PubMed PMID: 22689578; PubMed Central PMCID: PMC3406680. 
48. Suda T, Liu D. Hydrodynamic gene delivery: its principles and applications. Molecular therapy : the journal of the American Society of Gene Therapy. 2007;15(12):20639. doi: 10.1038/sj.mt.6300314. PubMed PMID: 17912237.

49. Agger EM, Rosenkrands I, Hansen J, Brahimi K, Vandahl BS, Aagaard C, et al. Cationic liposomes formulated with synthetic mycobacterial cordfactor (CAF01): a versatile adjuvant for vaccines with different immunological requirements. PLoS ONE. 2008;3(9):e3116. PubMed PMID: 18776936.

50. Desel C, Werninghaus K, Ritter M, Jozefowski K, Wenzel J, Russkamp N, et al. The Mincle-activating adjuvant TDB induces MyD88-dependent Th1 and Th17 responses through IL-1R signaling. PLoS One. 2013;8(1):e53531. doi: 10.1371/journal.pone.0053531. PubMed PMID: 23308247; PubMed Central PMCID: PMC3538599.

51. Sato K, Yang XL, Yudate T, Chung JS, Wu J, Luby-Phelps K, et al. Dectin-2 is a pattern recognition receptor for fungi that couples with the $\mathrm{Fc}$ receptor gamma chain to induce innate immune responses. J Biol Chem. 2006;281:38854-66. PubMed PMID: 17050534.

52. Arce I, Martinez-Munoz L, Roda-Navarro P, Fernandez-Ruiz E. The human C-type lectin CLECSF8 is a novel monocyte/macrophage endocytic receptor. Eur J Immunol. 2004;34(1):210-20. Epub 2004/02/19. doi: 10.1002/eji.200324230. PubMed PMID: 14971047.

53. Rajaram MVS, Arnett E, Azad AK, Guirado E, Ni B, Gerberick AD, et al. M. tuberculosis-Initiated Human Mannose Receptor Signaling Regulates Macrophage Recognition and Vesicle Trafficking by FcRgamma-Chain, Grb2, and SHP-1. Cell reports. 2017;21(1):126-40. doi: 10.1016/j.celrep.2017.09.034. PubMed PMID: 28978467.

54. Geijtenbeek TB, Van Vliet SJ, Koppel EA, Sanchez-Hernandez M, VandenbrouckeGrauls CM, Appelmelk B, et al. Mycobacteria target DC-SIGN to suppress dendritic cell function. J Exp Med. 2003;197(1):7-17. PubMed PMID: 12515809.

55. Melo MD, Catchpole IR, Haggar G, Stokes RW. Utilization of CD11b knockout mice to characterize the role of complement receptor $3(\mathrm{CR} 3, \mathrm{CD} 11 \mathrm{~b} / \mathrm{CD} 18)$ in the growth of Mycobacterium tuberculosis in macrophages. Cell Immunol. 2000;205(1):13-23. Epub 2000/11/18. doi: 10.1006/cimm.2000.1710. PubMed PMID: 11078603.

56. van der Vlugt LE, Labuda LA, Ozir-Fazalalikhan A, Lievers E, Gloudemans AK, Liu $\mathrm{KY}$, et al. Schistosomes induce regulatory features in human and mouse CD1d(hi) B cells: inhibition of allergic inflammation by IL-10 and regulatory T cells. PLoS One. 2012;7(2):e30883. Epub 2012/02/22. doi: 10.1371/journal.pone.0030883. PubMed PMID: 22347409 ; PubMed Central PMCID: PMCPMC3275567.

57. Feng X, Classon C, Teran G, Yang Y, Li L, Chan S, et al. Atrophy of skin-draining lymph nodes predisposes for impaired immune responses to secondary infection in mice with chronic intestinal nematode infection. PLoS Pathog. 2018;14(5):e1007008. Epub 2018/05/18. doi: 10.1371/journal.ppat.1007008. PubMed PMID: 29772005; PubMed Central PMCID: PMCPMC5957330.

58. Bhattacharjee S, Mejias-Luque R, Loffredo-Verde E, Toska A, Flossdorf M, Gerhard $\mathrm{M}$, et al. Concomitant Infection of S. mansoni and H. pylori Promotes Promiscuity of Antigen-Experienced Cells and Primes the Liver for a Lower Fibrotic Response. Cell reports. 2019;28(1):231-44 e5. Epub 2019/07/04. doi: 10.1016/j.celrep.2019.05.108. PubMed PMID: 31269443.

59. Stappers MHT, Nikolakopoulou C, Wiesner DL, Yuecel R, Klein BS, Willment JA, et al. Characterization of antifungal C-type lectin receptor expression on murine epithelial and 
endothelial cells in mucosal tissues. Eur J Immunol. 2021. Epub 2021/06/12. doi: 10.1002/eji.202149192. PubMed PMID: 34114658.

60. Schramm G, Suwandi A, Galeev A, Sharma S, Braun J, Claes AK, et al. Schistosome Eggs Impair Protective Th1/Th17 Immune Responses Against Salmonella Infection. Frontiers in immunology. 2018;9:2614. Epub 2018/11/30. doi: 10.3389/fimmu.2018.02614. PubMed PMID: 30487793; PubMed Central PMCID: PMCPMC6246638.

61. Reinink P, Buter J, Mishra VK, Ishikawa E, Cheng TY, Willemsen PTJ, et al. Discovery of Salmonella trehalose phospholipids reveals functional convergence with mycobacteria. J Exp Med. 2019;216(4):757-71. Epub 2019/02/26. doi: 10.1084/jem.20181812. PubMed PMID: 30804000; PubMed Central PMCID: PMCPMC6446866.

62. Park H, Li Z, Yang XO, Chang SH, Nurieva R, Wang YH, et al. A distinct lineage of CD4 T cells regulates tissue inflammation by producing interleukin 17. Nat Immunol. 2005;6(11):1133-41. PubMed PMID: 16200068.

63. Harrington LE, Hatton RD, Mangan PR, Turner H, Murphy TL, Murphy KM, et al. Interleukin 17-producing CD4+ effector T cells develop via a lineage distinct from the T helper type 1 and 2 lineages. Nat Immunol. 2005;6(11):1123-32. PubMed PMID: 16200070.

64. Paludan SR. Interleukin-4 and interferon-gamma: the quintessence of a mutual antagonistic relationship. Scand J Immunol. 1998;48(5):459-68. Epub 1998/11/20. doi: 10.1046/j.1365-3083.1998.00435.x. PubMed PMID: 9822252.

65. Babu S, Bhat SQ, Kumar NP, Anuradha R, Kumaran P, Gopi PG, et al. Attenuation of toll-like receptor expression and function in latent tuberculosis by coexistent filarial infection with restoration following antifilarial chemotherapy. PLoS neglected tropical diseases. 2009;3(7):e489. doi: 10.1371/journal.pntd.0000489. PubMed PMID: 19636364; PubMed Central PMCID: PMC2710006.

66. Babu S, Blauvelt CP, Kumaraswami V, Nutman TB. Diminished expression and function of TLR in lymphatic filariasis: a novel mechanism of immune dysregulation. J Immunol. 2005;175(2):1170-6. PubMed PMID: 16002719.

67. Babu S, Bhat SQ, Kumar NP, Jayantasri S, Rukmani S, Kumaran P, et al. Human type 1 and 17 responses in latent tuberculosis are modulated by coincident filarial infection through cytotoxic T lymphocyte antigen-4 and programmed death-1. J Infect Dis. 2009;200(2):288-98. doi: 10.1086/599797. PubMed PMID: 19505258; PubMed Central PMCID: PMC2997351.

68. George PJ, Anuradha R, Kumaran PP, Chandrasekaran V, Nutman TB, Babu S. Modulation of mycobacterial-specific Th1 and Th17 cells in latent tuberculosis by coincident hookworm infection. J Immunol. 2013;190(10):5161-8. doi: 10.4049/jimmunol.1203311. PubMed PMID: 23576678; PubMed Central PMCID: PMC3646958.

69. Wells CA, Salvage-Jones JA, Li X, Hitchens K, Butcher S, Murray RZ, et al. The macrophage-inducible C-type lectin, mincle, is an essential component of the innate immune response to Candida albicans. J Immunol. 2008;180(11):7404-13. PubMed PMID: 18490740.

70. Takai T, Li M, Sylvestre D, Clynes R, Ravetch JV. FcR gamma chain deletion results in pleiotrophic effector cell defects. Cell. 1994;76(3):519-29. PubMed PMID: 8313472.

71. Liu F, Song Y, Liu D. Hydrodynamics-based transfection in animals by systemic administration of plasmid DNA. Gene therapy. 1999;6(7):1258-66. doi: 10.1038/sj.gt.3300947. PubMed PMID: 10455434. 
Figure 1: IL-4 impairs upregulation of MINCLE and other DECTIN-2 family CLR in

macrophages stimulated with BCG. (A-D) C57BL/6 BMM were stimulated as indicated in presents or absence of IL-4 for 6, 24 or 48h. MINCLE (A), DECTIN-2 (B), MCL (C), and DECTIN-1 (D) mRNA expression was determined by qRT-PCR shown as fold change indicated MOI in the presence or absence of IL-4 for 24 hours, followed by staining of MINCLE expression. Representative stainings are shown as histogram overlay (left panel), for quantification (right panel) the median fluorescence intensity of the isotype control staining was subtracted from MINCLE signal to obtain the $\triangle \mathrm{MFI}$. Each point represents one mouse, pooled from two experiments. ${ }^{*} \mathrm{p}<0.05, * * \mathrm{p}<0.01, * * * \mathrm{p}<0.001$

Representative histograms show phagocytosis of BCG by detection of fluorescent DsRed signal

BMM were stimulated with BCG for $24 \mathrm{~h}$. Production of G-CSF and TNF was measured from 

were hydrodynamically injected with $0.25 \mu \mathrm{g}$ or $0.5 \mu \mathrm{g}$ of IL-4 plasmid (i.v.) or Ringer solution.

804

805 5 days $(0.5 \mu \mathrm{g})$ or 7 days later $(0.25 \mu \mathrm{g})$ mice were sacrificed and serum IL-4 levels were determined via ELISA $(\mathrm{n}=6-7$ mice per group). n.d. = not detectable. $(\mathbf{B}, \mathbf{C}) 0.25 \mu \mathrm{g}$ of IL-4 plasmid or Ringer solution was hydrodynamically injected into C57BL/6 wildtype mice. 2 days later mice were infected i.p. with $40 \times 10^{6} \mathrm{CFU}$ of $M$. bovis BCG. (B) Generic gating strategy for flow cytometry data. Monocytes were characterized as lineage-CD11 ${ }^{+}$SiglecF$^{-} \mathrm{Ly}^{-} \mathrm{C}^{+}$cells. Neutrophils were characterized as lineage-CD11 ${ }^{+}$SiglecF-Ly6G ${ }^{+}$cells. Lineage marker: CD3, CD19, NK1.1. (C) Histograms depict MINCLE surface expression on Ly6C ${ }^{\text {hi }}$ monocytes and neutrophils $24 \mathrm{~h}$ p.i. analysed via flow cytometry. Quantitative analysis of MINCLE surface expression shown as median fluorescence intensity (MFI). Fluorescence minus one control (FMO) was substracted. Infected MINCLE-/- mice were used as staining controls to exclude unspecific binding of 4A9 antibody. Data is depicted from 2 independent experiments (2-7 mice per group in total, each dot corresponding to one mouse). ${ }^{*} \mathrm{p}<0.01$; ns $=$ not significant. (DE) C57BL/6 mice were s.c. infected with $N$. brasiliensis or left uninfected followed by M. bovis BCG-Dsred infection (40x10^6 CFU/mouse) on day 10 p.i. 24 h later mice were sacrificed. (D) Representative histograms of eosinophil population of BCG-infected and N. brasiliensis coinfected mouse. Bar graphs show relative percentage of myeloid cell populations as indicated. (E) MINCLE surface expression was analyzed on peritoneal Ly6 $\mathrm{C}^{\text {hi }}$ monocytes and neutrophils via flow cytometry. Quantitative analysis of MINCLE surface expression shown as median fluorescence intensity (MFI) normalized to BCG infected mice. Fluorescence minus one control (FMO) was substracted. Data is depicted from 3 independent experiments (12-13 mice per group in total). ${ }^{*} \mathrm{p}<0.05,{ }^{*} \mathrm{p}<0.01,{ }^{* * *} \mathrm{p}<0.001$. (F) $\mathrm{C} 57 \mathrm{BL} / 6$ mice were s.c. infected with 


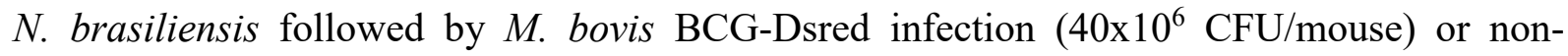
fluorescent BCG (nf) on day 10 p.i. $24 \mathrm{~h}$ after BCG infection, phagocytosis was measured by detection of PE signal in monocytes or neutrophils. Quantitative analysis of the percentage of BCG-positive monocytes.

Figure 4: Co-infection with Schistosoma mansoni (S.m.) suppresses Th1/Th17 induction and spleen cells were re-stimulated with $\mathrm{H} 1$ in vitro. Draining inguinal lymph node cells or splenocytes were restimulated with H1 or anti-CD3 for 96 h. IL-17, IFN $\gamma$, IL-10 and IL-4 production was measured from cell culture supernatants by ELISA. Data is shown from 3 independent experiments ( $\mathrm{n}=18$ mice per group in total) for IFN $\gamma, \mathrm{IL}-17$ and IL-10 (C, D) and from 2 independent experiments for IL-4 (B). (E, F) Data is shown from 1 experiment $(\mathrm{n}=5$ mice per group in total). ${ }^{*} \mathrm{p}<0.05, * * \mathrm{p}<0.01, * * * \mathrm{p}<0.001$ experimental procedure. C57BL/6 mice were infected subcutaneously in the flank with $500 \mathrm{~L} 3$ larvae of $N$. brasiliensis in $200 \mu 1$ PBS. 5 days p.i. mice were immunized with H1/CAF01 (BF) or H1/G3D6A (G). 7 days after immunization, mice were sacrificed, and inguinal and 
were sacrificed (day 7 after immunization). The increase in footpad swelling is shown as mean

$850+$ SD for the indicated time points $(n=10-11$ mice for each data point $)$. (C) Absolute cell

851 number of draining inguinal and popliteal lymph node cells (LN) and spleen on day 7 after

852 H1/CAF01. (D-G) Draining inguinal and popliteal lymph node cells or splenocytes were

853 restimulated with $\mathrm{H} 1$, anti-CD3 or left untreated (mock) for $96 \mathrm{~h}$, followed by cytokine

854 determination by ELISA. (D) IL-4 levels produced by draining lymph node cells (left) or

855 splenocytes (right). (E, F) IL-17, IFN $\gamma$ and IL-10 cytokine production by draining lymph node

856 cells (E) and splenocytes (F). (G) Immunization of C57BL/6 mice with H1 in G3D6A adjuvant.

8577 days after immunization mice were sacrificed and splenocytes were treated as described in

858 (D, E). All data is shown from two $(\mathbf{B}-\mathbf{F})$ or three $(\mathbf{G})$ independent experiments $(\mathrm{n}=10-14$ mice 


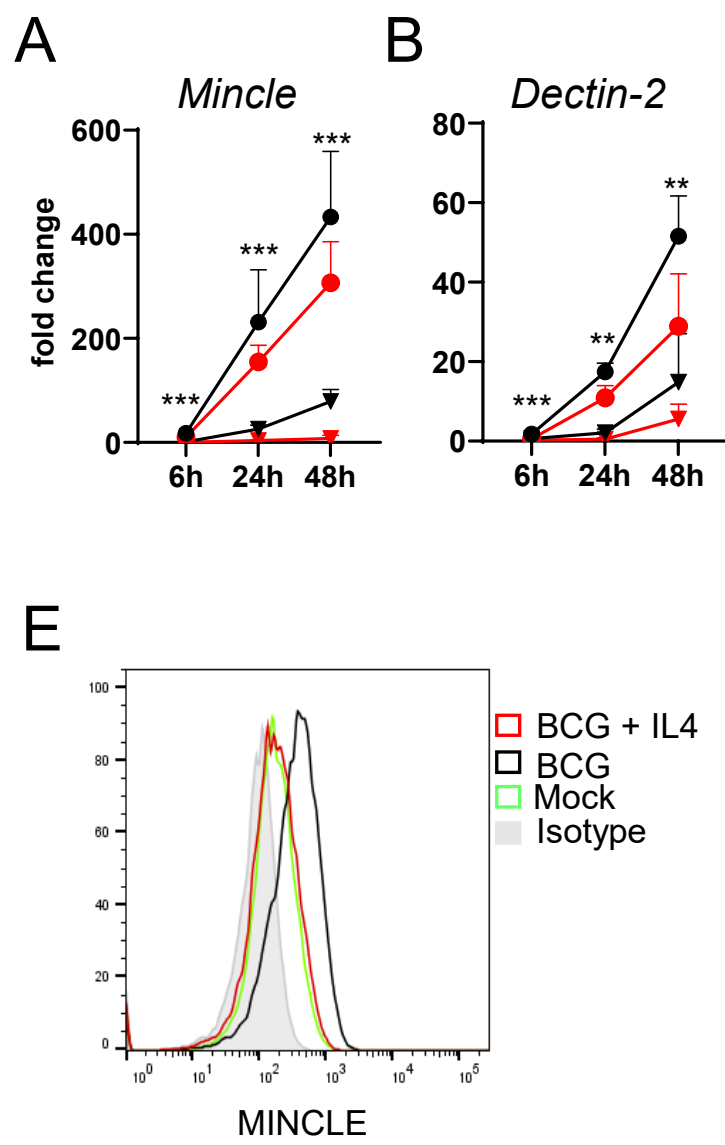

C

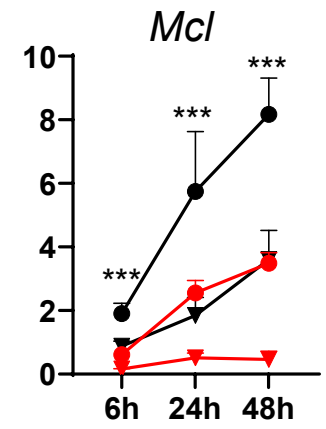

$\mathrm{D}$
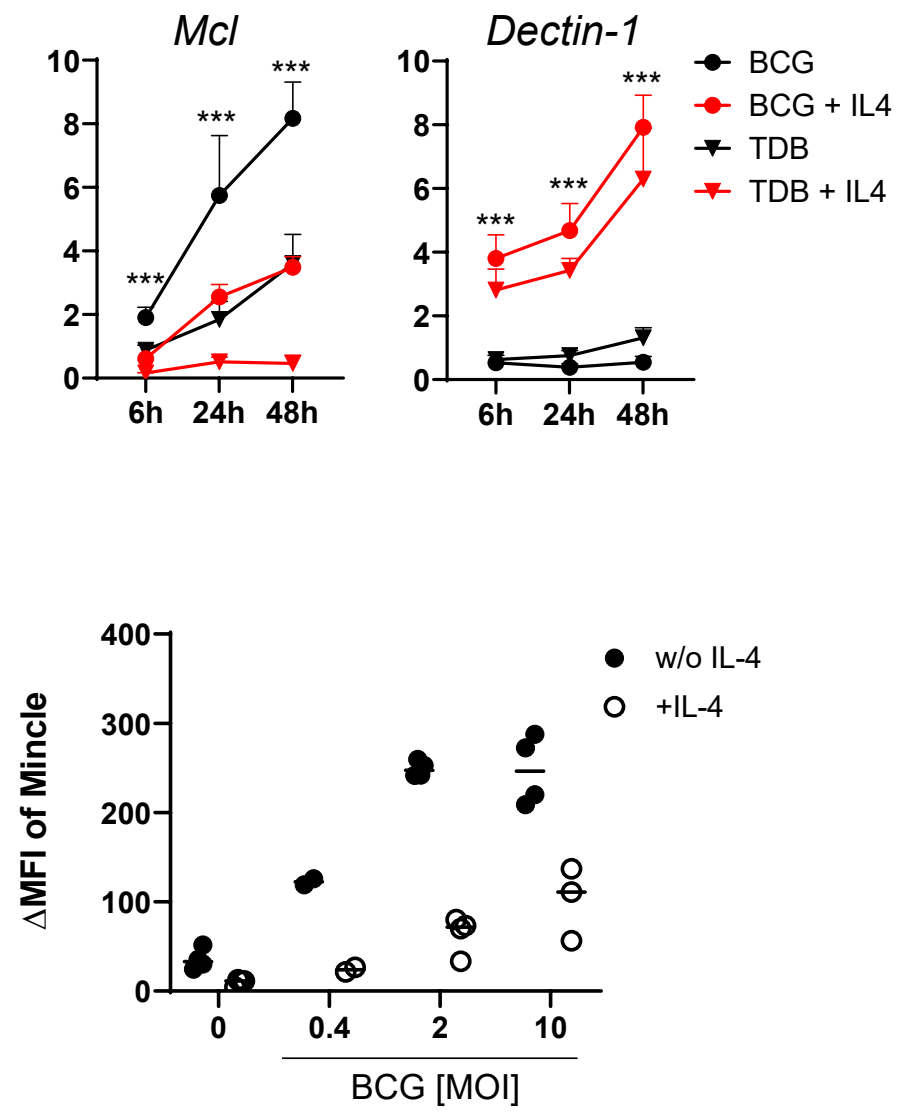

Figure 1

Figure 1: IL-4 impairs upregulation of MINCLE and other DECTIN-2 family CLR in macrophages stimulated with BCG. (A-D) C57BL/6 BMM were stimulated as indicated in presents or absence of IL4 for 6, 24 or 48h. MINCLE (A), DECTIN-2 (B), MCL (C), and DECTIN-1 (D) mRNA expression was determined by qRT-PCR shown as fold change calibrated to unstimulated control. Data are depicted as mean + SD from two independent experiments performed in biological duplicates. (E) BMM were stimulated with BCG at the indicated MOI in the presence or absence of IL-4 for 24 hours, followed by staining of MINCLE expression. Representative stainings are shown as histogram overlay (left panel), for quantification (right panel) the median fluorescence intensity of the isotype control staining was subtracted from MINCLE signal to obtain the $\triangle$ MFI. Each point represents one mouse, pooled from two experiments. ${ }^{*} \mathrm{p}<0.05, * * \mathrm{p}<0.01, * * * \mathrm{p}<0.001$. 
A
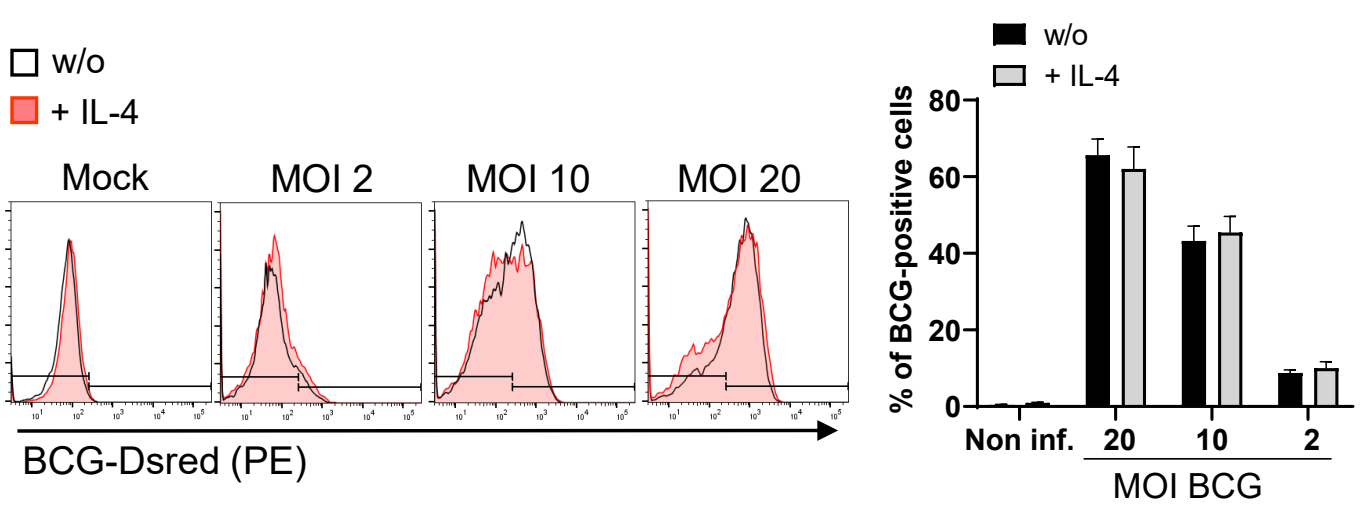

B

G-CSF

TNF
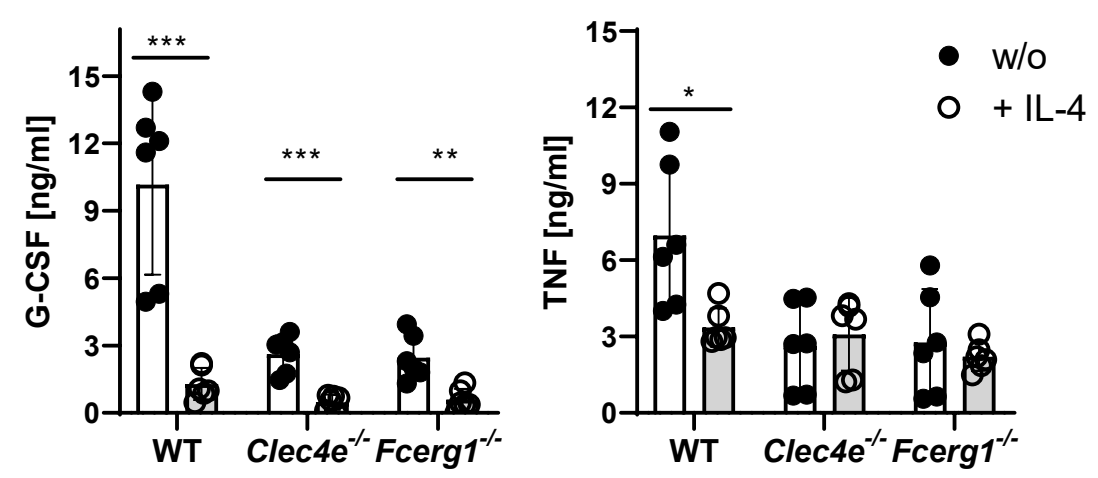

Figure 2

Figure 2: IL-4 does not affect phagocytosis of BCG but inhibits cytokine production. (A) C57BL/6 BMM were infected with different MOI of fluorescent BCG-Dsred co-treated with IL-4 or not as indicated. Phagocytic uptake was measured via flow cytometry. (A) Representative histograms show phagocytosis of BCG by detection of fluorescent DsRed signal in BMMs. Quantitative analysis of phagocytosis based on percentage of BCG-positive cells at 6 and $24 \mathrm{~h}$ post infection. Data is depicted from 2-3 independent experiments performed in biological duplicates. (B) C57BL/6 (WT), MINCLE knockout $\left(\mathrm{Clec}_{4} \mathrm{e}^{-/}\right)$and $\mathrm{FcR} \gamma\left(\mathrm{Fcergl}^{-/-}\right) \mathrm{BMM}$ were stimulated with BCG for $24 \mathrm{~h}$. Production of GCSF and TNF was measured from cell culture supernatants via ELISA. Data is depicted from 3 independent experiments performed in biological duplicates. ${ }^{*} \mathrm{p}<0.05,{ }^{*} \mathrm{p}<0.01,{ }^{* * *} \mathrm{p}<0.001$. 
A

B
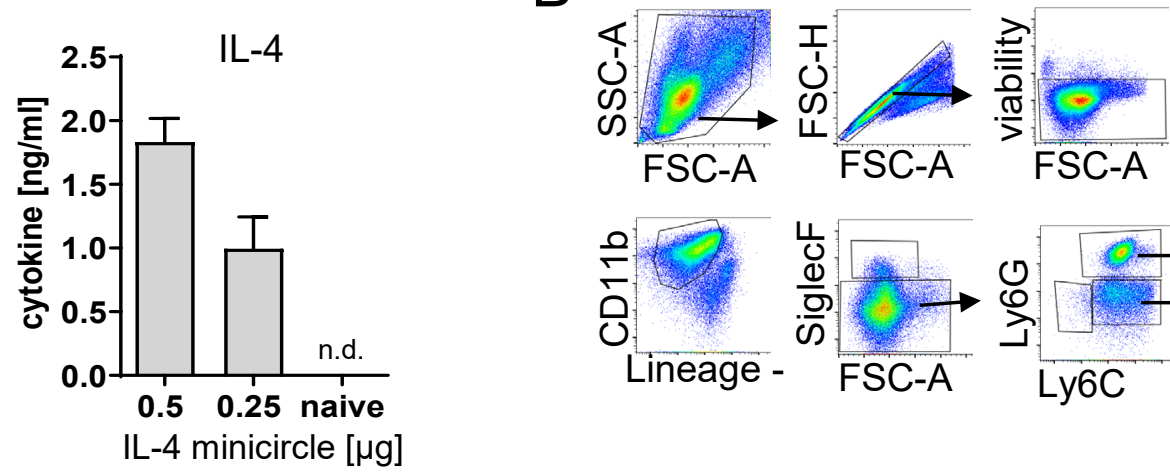

C

Ly6Chi

monocytes neutrophils
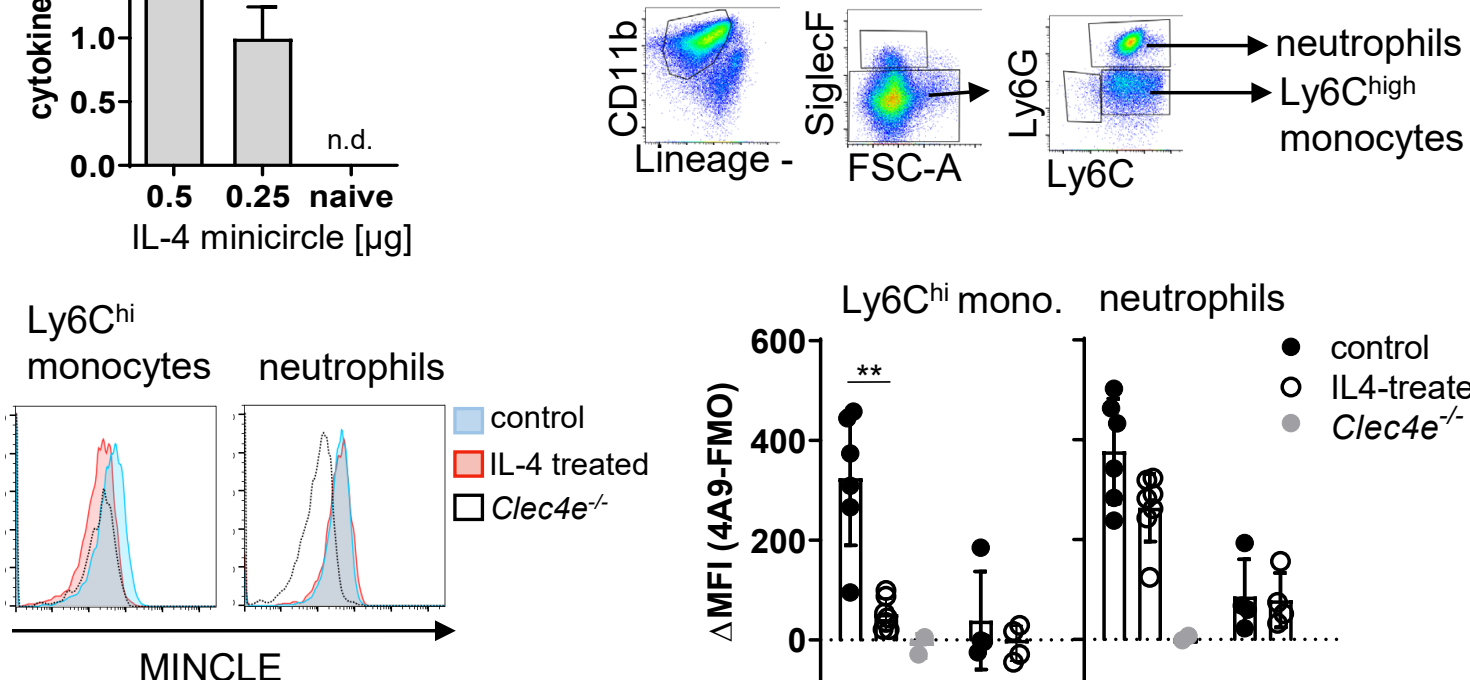

MINCLE

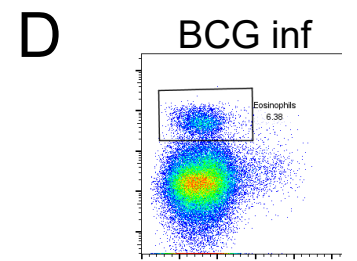

N.b. + BCG inf

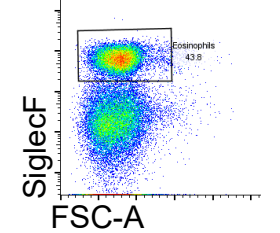

E Ly6Chi $^{\text {hi }}$

monocytes neutrophils
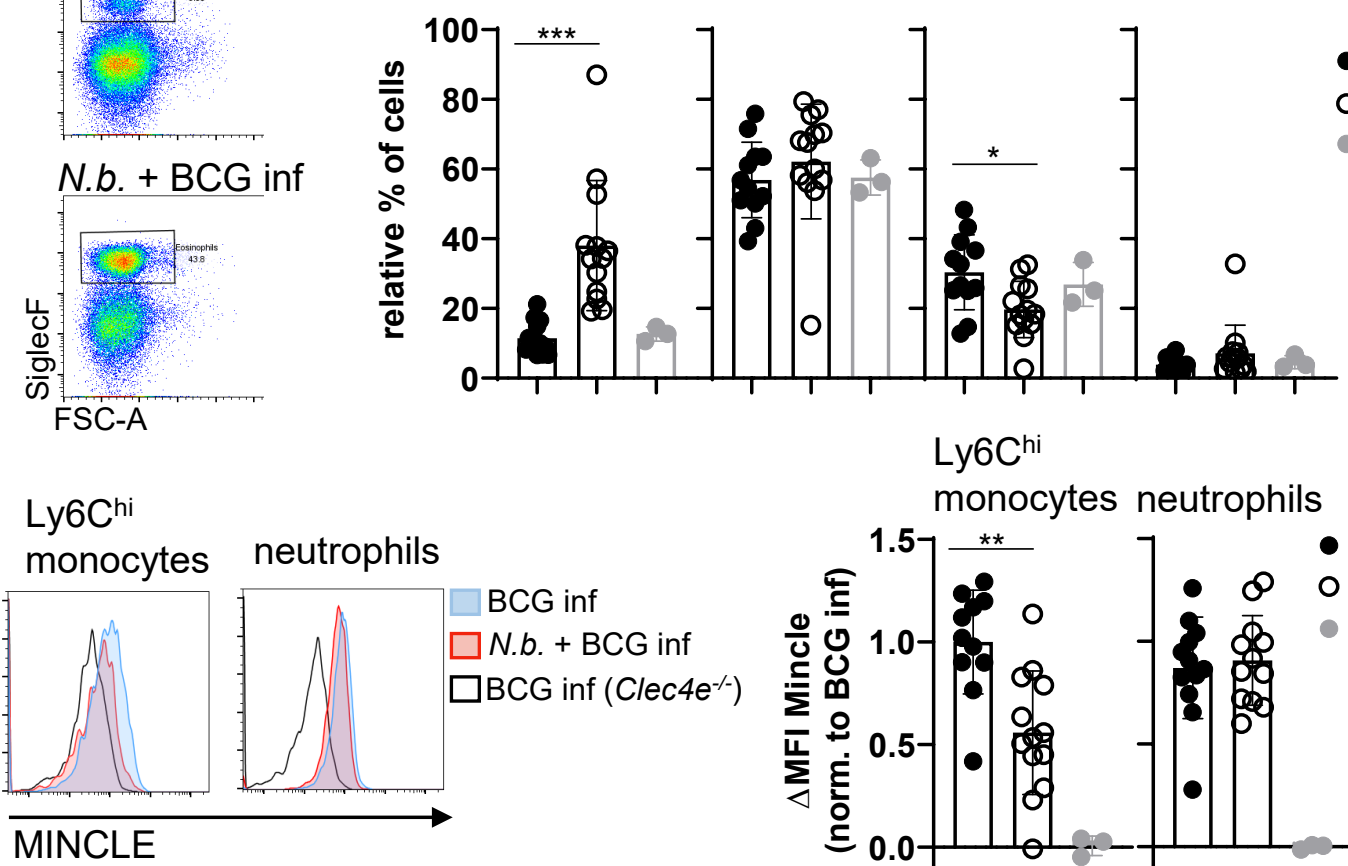

- BCG inf

- N.b. + BCG inf

- $\operatorname{BCG} \inf \left(\mathrm{Clec} \mathrm{e}^{-/}\right)$

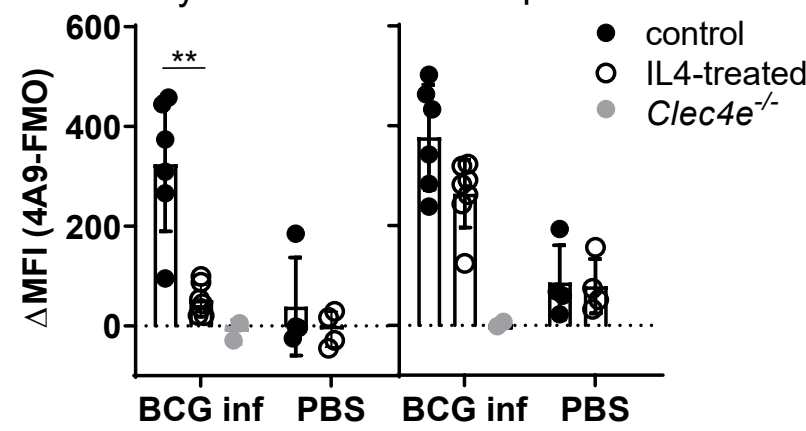

Ly6C hi Ly6Clow

eosinophils neutrophils monocytes monocytes

Ly6Chi

monocytes neutrophils

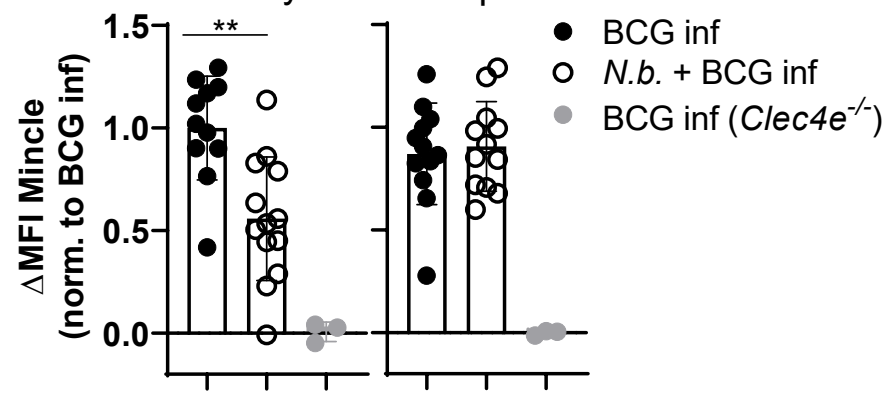

F Ly6Chi

monocytes neutrophils
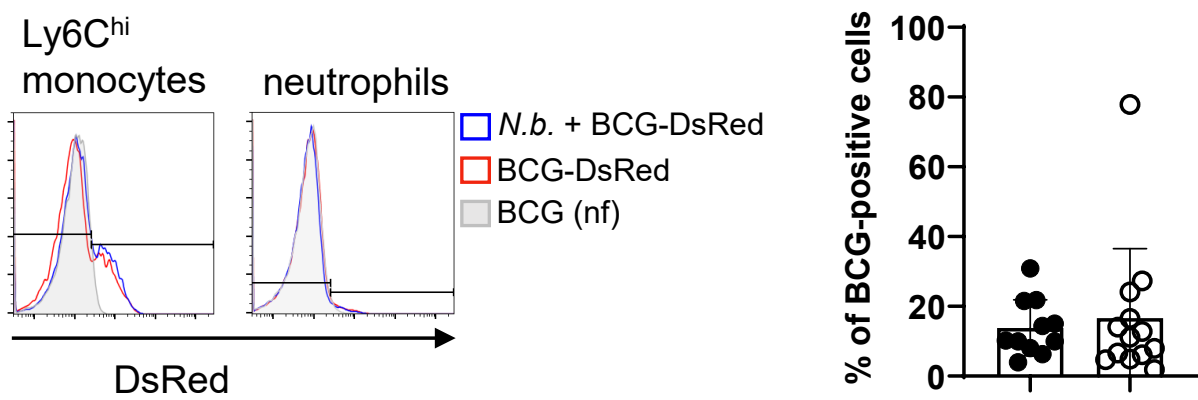

Figure 3 
Figure 3: Overexpression of IL-4 or co-infection with $N$. brasiliensis impair MINCLE upregulation on peritoneal monocytes but does not reduce phagocytosis upon BCG infection. (A) IL-4 concentration in serum of mice injected with IL-4 minicircle. C57BL/6 mice were hydrodynamically injected with $0.25 \mu \mathrm{g}$ or $0.5 \mu \mathrm{g}$ of IL-4 plasmid (i.v.) or Ringer solution. 5 days ( 0.5 $\mu \mathrm{g})$ or 7 days later $(0.25 \mu \mathrm{g})$ mice were sacrificed and serum IL-4 levels were determined via ELISA $(\mathrm{n}=6-7$ mice per group). n.d. = not detectable. $(\mathbf{B}, \mathbf{C}) 0.25 \mu \mathrm{g}$ of IL-4 plasmid or Ringer solution was hydrodynamically injected into C57BL/6 wildtype mice. 2 days later mice were infected i.p. with 40x $10^{6}$ CFU of $M$. bovis BCG. (B) Generic gating strategy for flow cytometry data. Monocytes were characterized as lineage-CD $11 \mathrm{~b}^{+}$SiglecF-Ly6 $\mathrm{C}^{+}$cells. Neutrophils were characterized as lineage $\mathrm{CD}_{11 b^{+} \text {SiglecF-Ly6G }}^{+}$cells. Lineage marker: CD3, CD19, NK1.1. (C) Histograms depict MINCLE surface expression on Ly6 $\mathrm{Chi}^{\text {hi }}$ monocytes and neutrophils $24 \mathrm{~h}$ p.i. analysed via flow cytometry. Quantitative analysis of MINCLE surface expression shown as median fluorescence intensity (MFI). Fluorescence minus one control (FMO) was substracted. Infected Clec4 $e^{-/-}$mice were used as staining controls to exclude unspecific binding of 4A9 antibody. Data is depicted from 2 independent experiments (2-7 mice per group in total, each dot corresponding to one mouse). ${ }^{* *} \mathrm{p}<0.01$; ns $=$ not significant. (D-E) C57BL/6 mice were s.c. infected with $N$. brasiliensis or left uninfected followed by

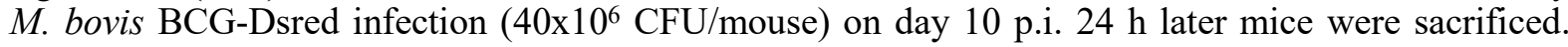
(D) Representative histograms of eosinophil population of BCG-infected and N. brasiliensis coinfected mouse. Bar graphs show relative percentage of myeloid cell populations as indicated. (E) MINCLE surface expression was analyzed on peritoneal Ly6C ${ }^{\text {hi }}$ monocytes and neutrophils via flow cytometry. Quantitative analysis of MINCLE surface expression shown as median fluorescence intensity (MFI) normalized to BCG infected mice. Fluorescence minus one control (FMO) was substracted. Data is depicted from 3 independent experiments (12-13 mice per group in total). ${ }^{*} \mathrm{p}<$ $0.05, * * \mathrm{p}<0.01, * * * \mathrm{p}<0.001$. (F) C57BL/6 mice were s.c. infected with $N$. brasiliensis followed by M. bovis BCG-Dsred infection (40x10 $10^{6} \mathrm{CFU} /$ mouse) or non-fluorescent BCG (nf) on day 10 p.i. $24 \mathrm{~h}$ after BCG infection, phagocytosis was measured by detection of $\mathrm{PE}$ signal in monocytes or neutrophils. Quantitative analysis of the percentage of BCG-positive monocytes. 
A

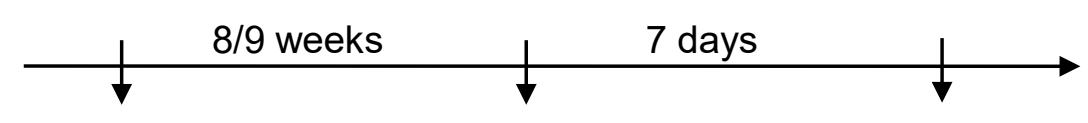

S.m.. infection

s.c. in flank
H1/CAF01 or CpG

s.c. in flank
Restimulation of LN/spleen cells with $\mathrm{H} 1$ in vitro

B
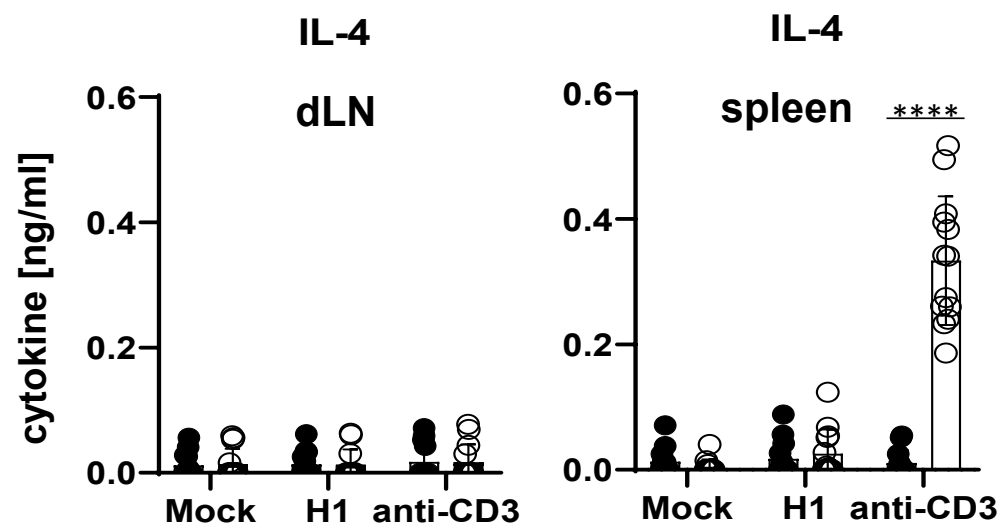

- non inf

- S.m. inf

C

IFN $\gamma$

IL-17

IL-10
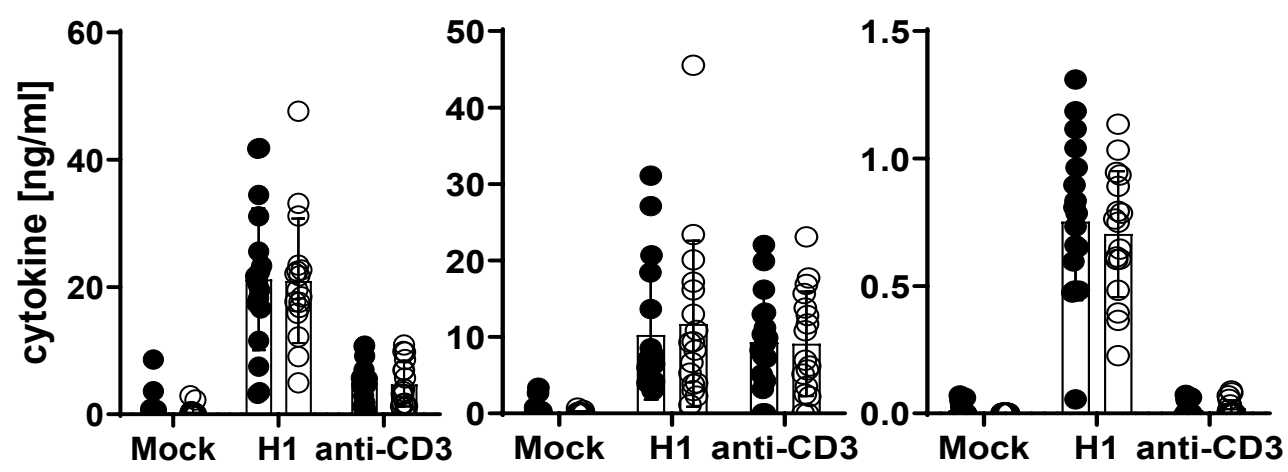

dLN

D
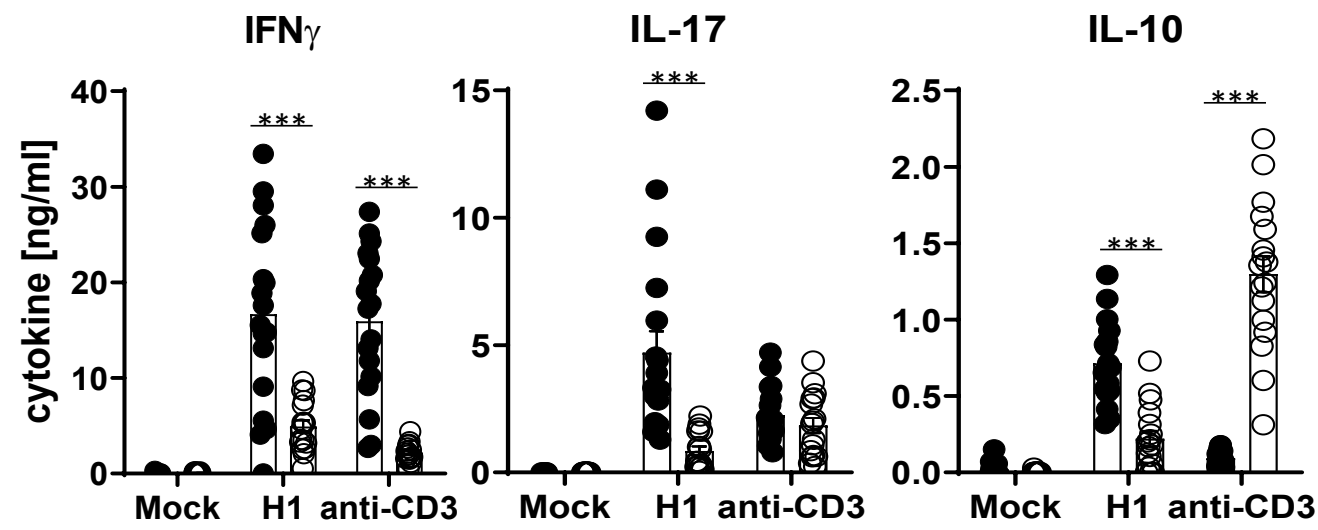

spleen

$E$

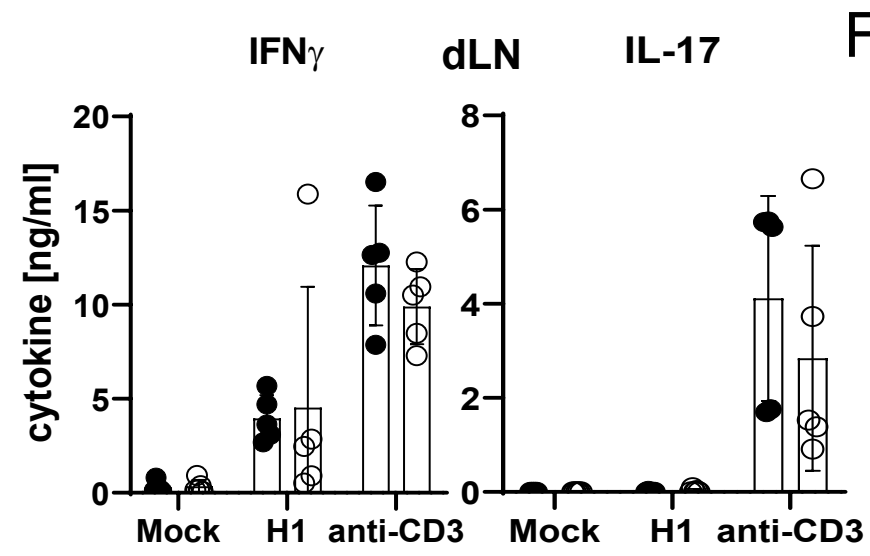

$F$

IFN $\gamma$

spleen

IL-17
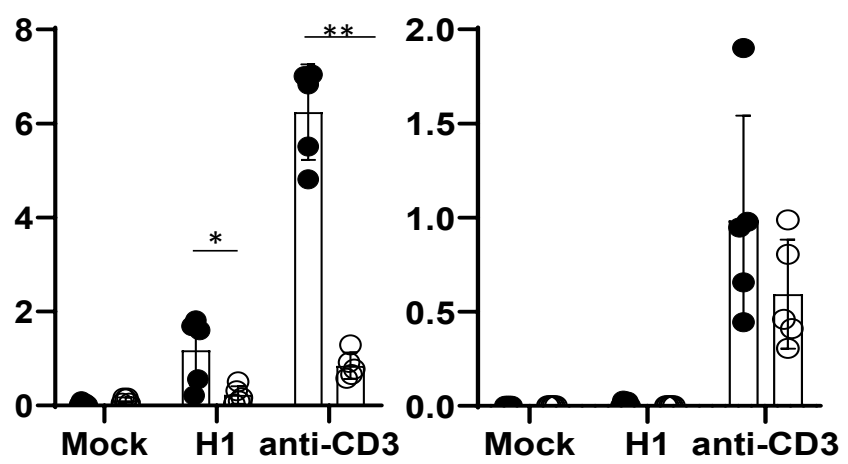

Figure 4 
Figure 4: Co-infection with Schistosoma mansoni (S.m.) suppresses Th1/Th17 induction by a MINCLE-dependent adjuvant in the spleen but not in the draining lymph node. (A) Scheme of experimental procedure. Cercariae of Schistosoma mansoni (S.m.) were injected s.c into C57BL/6 mice. 8 to 9 weeks p.i. mice were immunized with CAF01 (B, C, D) or CpG ODN (E, F). 7 days after immunization, mice were sacrificed and inguinal lymph node cells and spleen cells were re-stimulated with H1 in vitro. Draining inguinal lymph node cells or splenocytes were restimulated with H1 or antiCD3 for $96 \mathrm{~h}$. IL-17, IFN $\gamma$, IL-10 and IL-4 production was measured from cell culture supernatants by ELISA. Data is shown from 3 independent experiments $(\mathrm{n}=18$ mice per group in total) for IFN $\gamma$, IL17 and IL-10 (C, D) and from 2 independent experiments for IL-4 (B). (E, F) Data is shown from 1 experiment ( $\mathrm{n}=5$ mice per group in total). ${ }^{*} \mathrm{p}<0.05, * * \mathrm{p}<0.01, * * * \mathrm{p}<0.001$. 
A

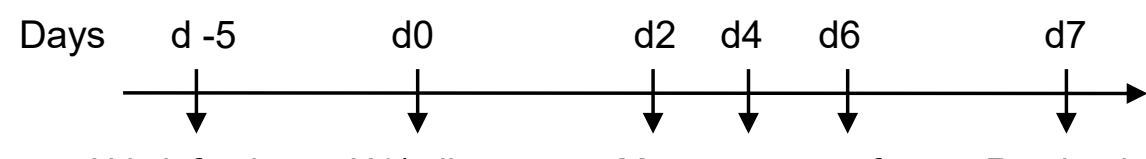

N.b. infection H1/adjuvant Measurement of

Restimulation of $L N /$ spleen cells

s.c. in flank s.c. footpad footpad thickness with $\mathrm{H} 1$ in vitro
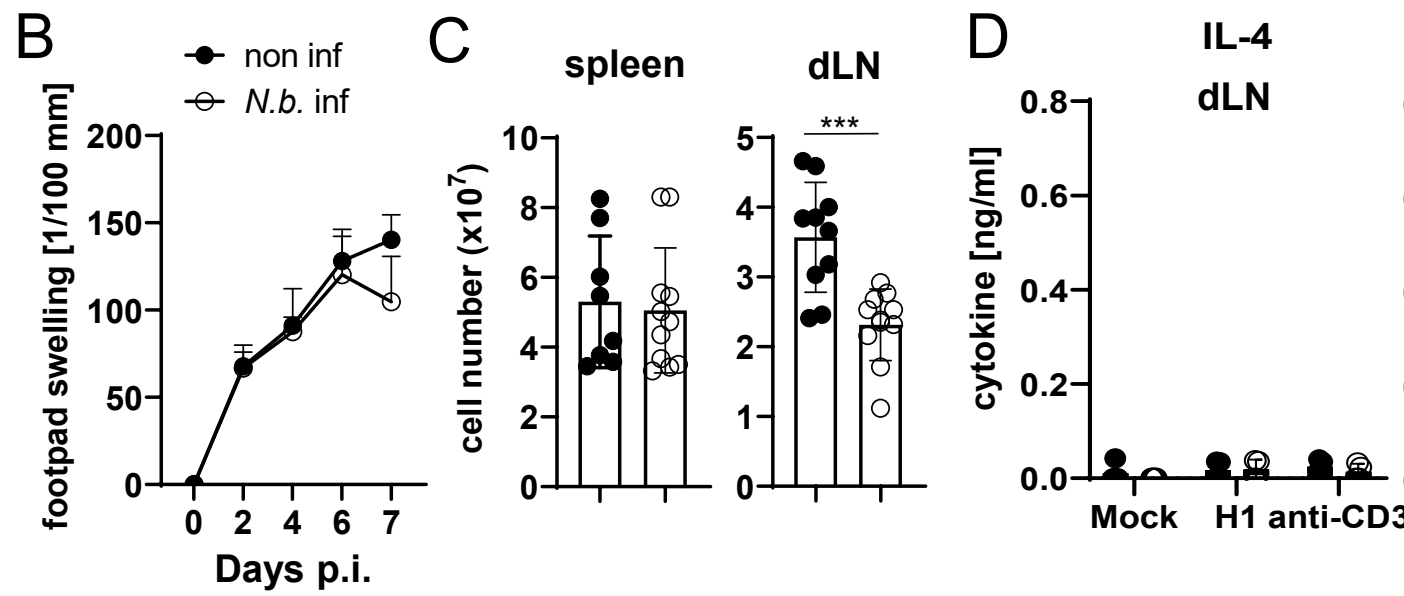

IL-4

E

IF $\gamma$

IL-17

IL-10
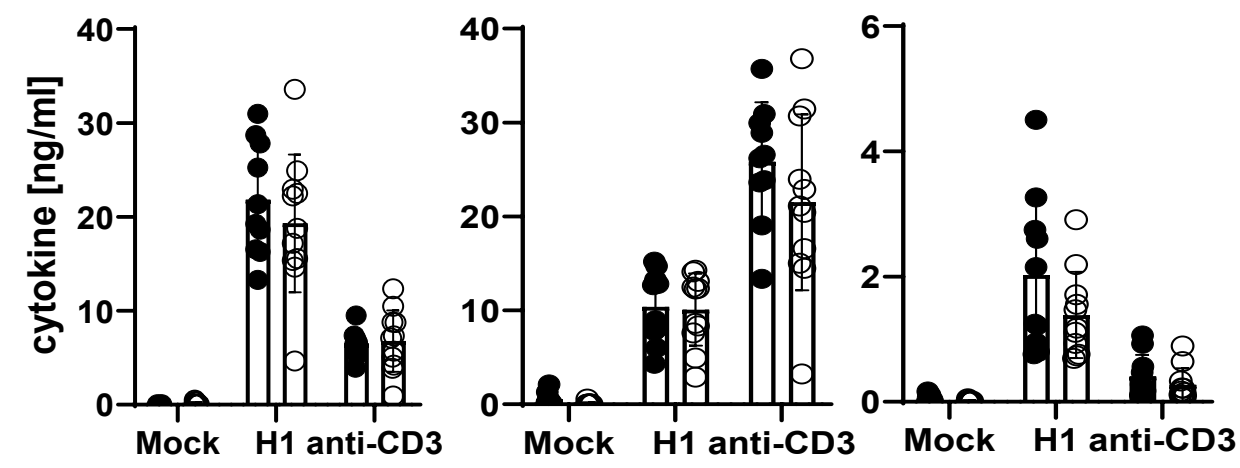

dLN

F

IFN $\gamma$

IL-17

IL-10
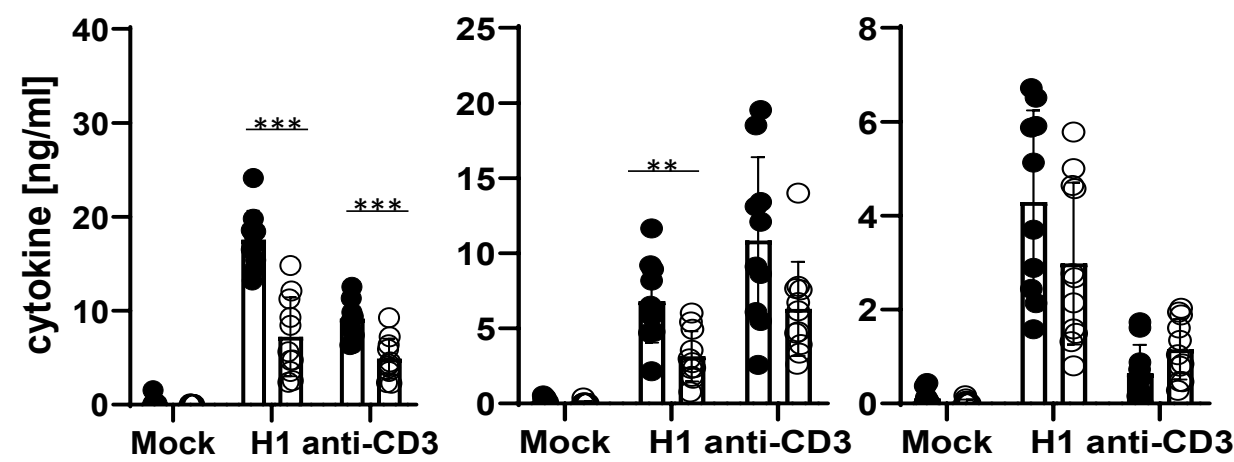

G

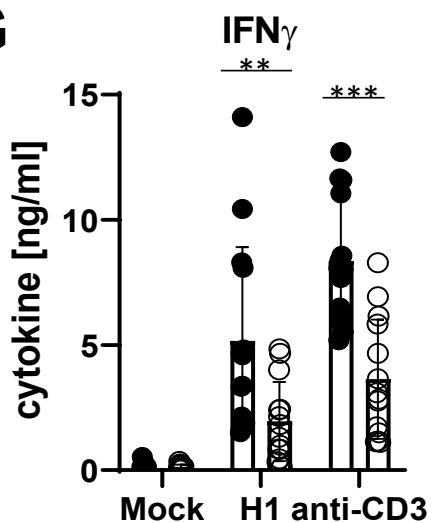

IL-17

IL-10

spleen

Figure 5
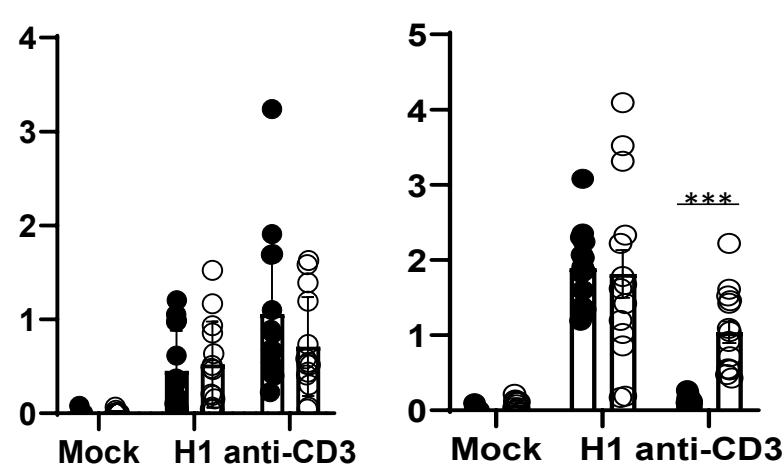

IL-4

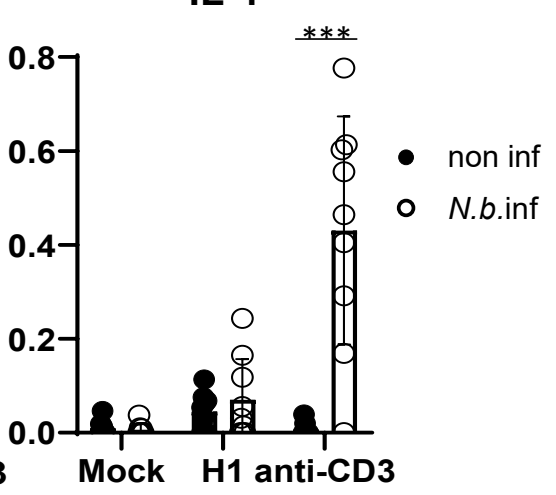


Figure 5: Co-infection with $N$. brasiliensis suppresses Th1/Th17 induction by a MINCLEdependent adjuvant in the spleen but not in the draining lymph node. (A) Scheme of experimental procedure. C57BL/6 mice were infected subcutaneously in the flank with 500 L3 larvae of $N$. brasiliensis in $200 \mu \mathrm{l} \mathrm{PBS.} 5$ days p.i. mice were immunized with H1/CAF01 (B-F) or H1/G3D6A (G). 7 days after immunization, mice were sacrificed, and inguinal and popliteal lymph node cells and spleen cells were re-stimulated with H1 in vitro. (B) Footpad swelling was measured over a period of 1 week after immunization with H1/CAF01 until mice were sacrificed (day 7 after immunization). The increase in footpad swelling is shown as mean + SD for the indicated time points ( $\mathrm{n}=10-11$ mice for each data point). (C) Absolute cell number of draining inguinal and popliteal lymph node cells (LN) and spleen on day 7 after H1/CAF01. (D-G) Draining inguinal and popliteal lymph node cells or splenocytes were restimulated with H1, anti-CD3 or left untreated (mock) for 96 $\mathrm{h}$, followed by cytokine determination by ELISA. (D) IL-4 levels produced by draining lymph node cells (left) or splenocytes (right). (E, F) IL-17, IFN $\gamma$ and IL-10 cytokine production by draining lymph node cells (E) and splenocytes (F). (G) Immunization of C57BL/6 mice with H1 in G3D6A adjuvant. 7 days after immunization mice were sacrificed and splenocytes were treated as described in (D, E). All data is shown from two $(\mathbf{B}-\mathbf{F})$ or three $(\mathbf{G})$ independent experiments $(\mathrm{n}=10-14$ mice per group in total). $\mathrm{p}<0.05, * * \mathrm{p}<0.01, * * * \mathrm{p}<0.001$. 